Supporting Information

\title{
A Highly Practical Instant Catalyst for Cyclotrimerization of Alkynes to Substituted Benzenes
}

Naoko Saino, Fumihiro Amemiya, Emi Tanabe, Kouki Kase and Sentaro Okamoto*

Department of Applied Chemistry, Kanagawa University, 3-27-1 Rokkakubashi, Kanagawa-ku, Yokohama 221-8686, Japan

E-mail: okamos10@kanagawa-u.ac.jp

File name: SI_nmr_1 
Table of Contents

File name

Contents

Pages

\begin{tabular}{|c|c|c|}
\hline \multirow{19}{*}{$\begin{array}{l}\text { SI_text } \\
\text { SI_nmr_1 }\end{array}$} & Experimental Procedures \& Spectral Data (text) & \\
\hline & ${ }^{1} \mathrm{H}$ and ${ }^{13} \mathrm{C}$ NMR Spectra & For ${ }^{1} \mathrm{H}$, for ${ }^{13} \mathrm{C}$ \\
\hline & Compound 10a & 2,3 \\
\hline & Compound 10b & 4,5 \\
\hline & Compound 10c & 6,7 \\
\hline & Compound 5aa & 8,9 \\
\hline & Compound 5ab & 10,11 \\
\hline & Compound 5ac & 12,13 \\
\hline & By-product \#1 in the 5ac-forming reaction & 14,15 \\
\hline & By-product \#2 in the 5ac-forming reaction & 16,17 \\
\hline & Compound 5ad & 18,19 \\
\hline & Compound 5af & 20,21 \\
\hline & Compound 5ag & 22,23 \\
\hline & Compound 5ah & 24,25 \\
\hline & Compound 5ai & 26,27 \\
\hline & Compound 5aj & 28,29 \\
\hline & Compound 5ak & 30,31 \\
\hline & Compound 5al & 32,33 \\
\hline & Compound 5am & 34,35 \\
\hline SI_nmr_2 & 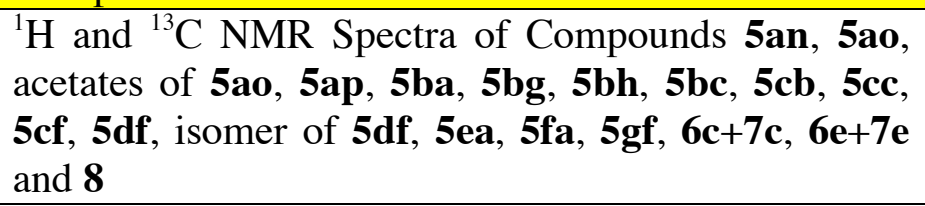 & \\
\hline
\end{tabular}




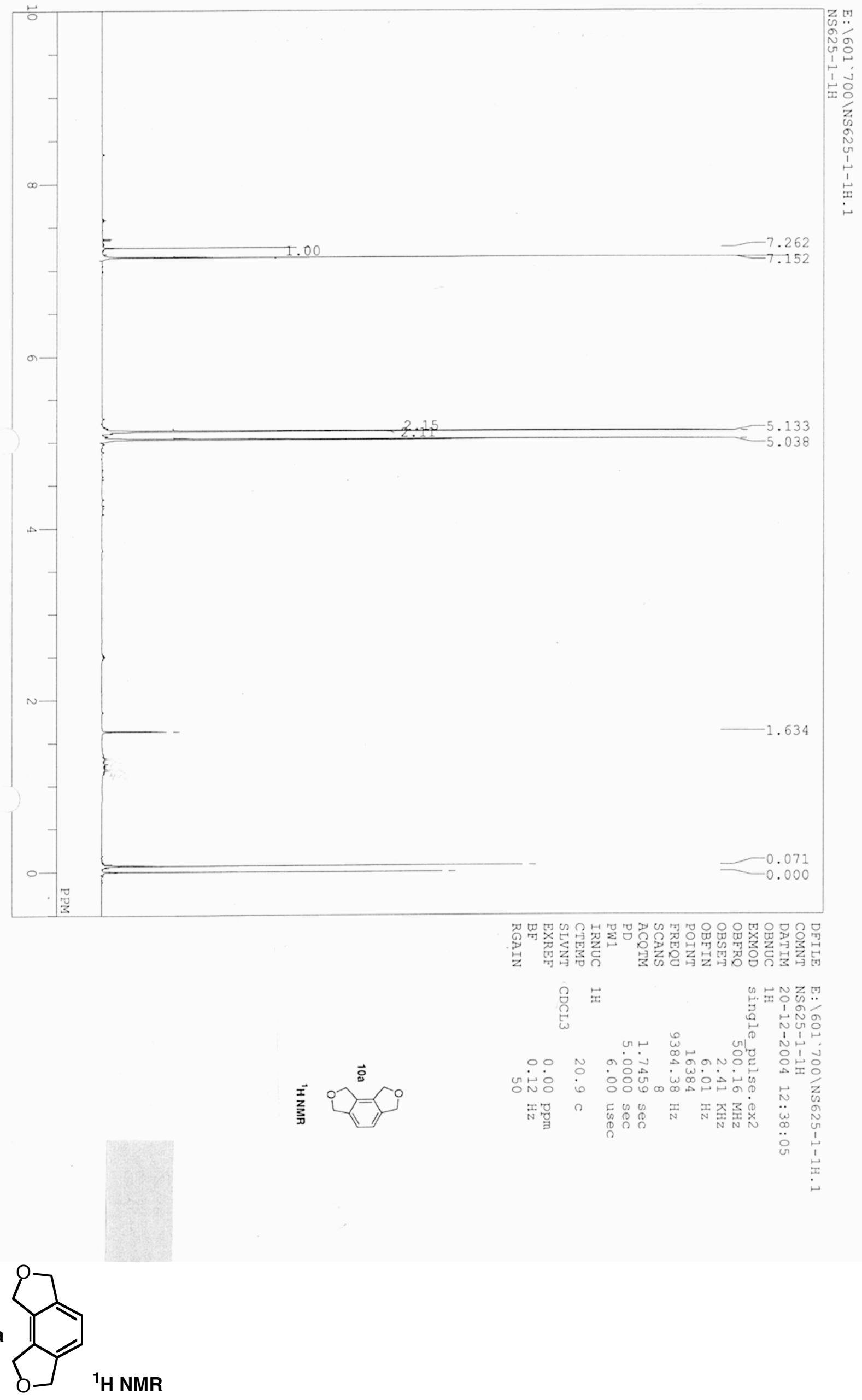

Page: 2 


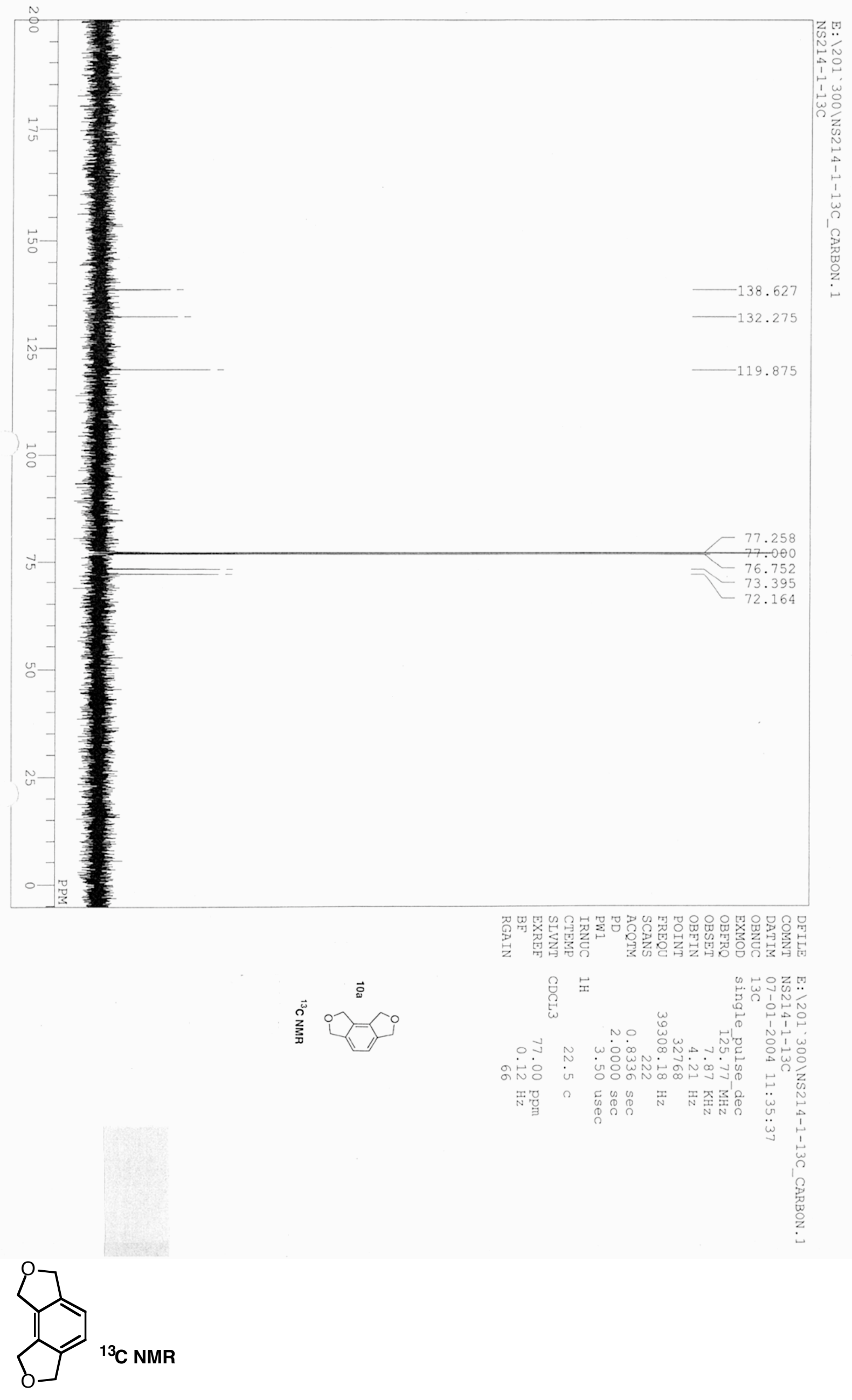

Page: 3 


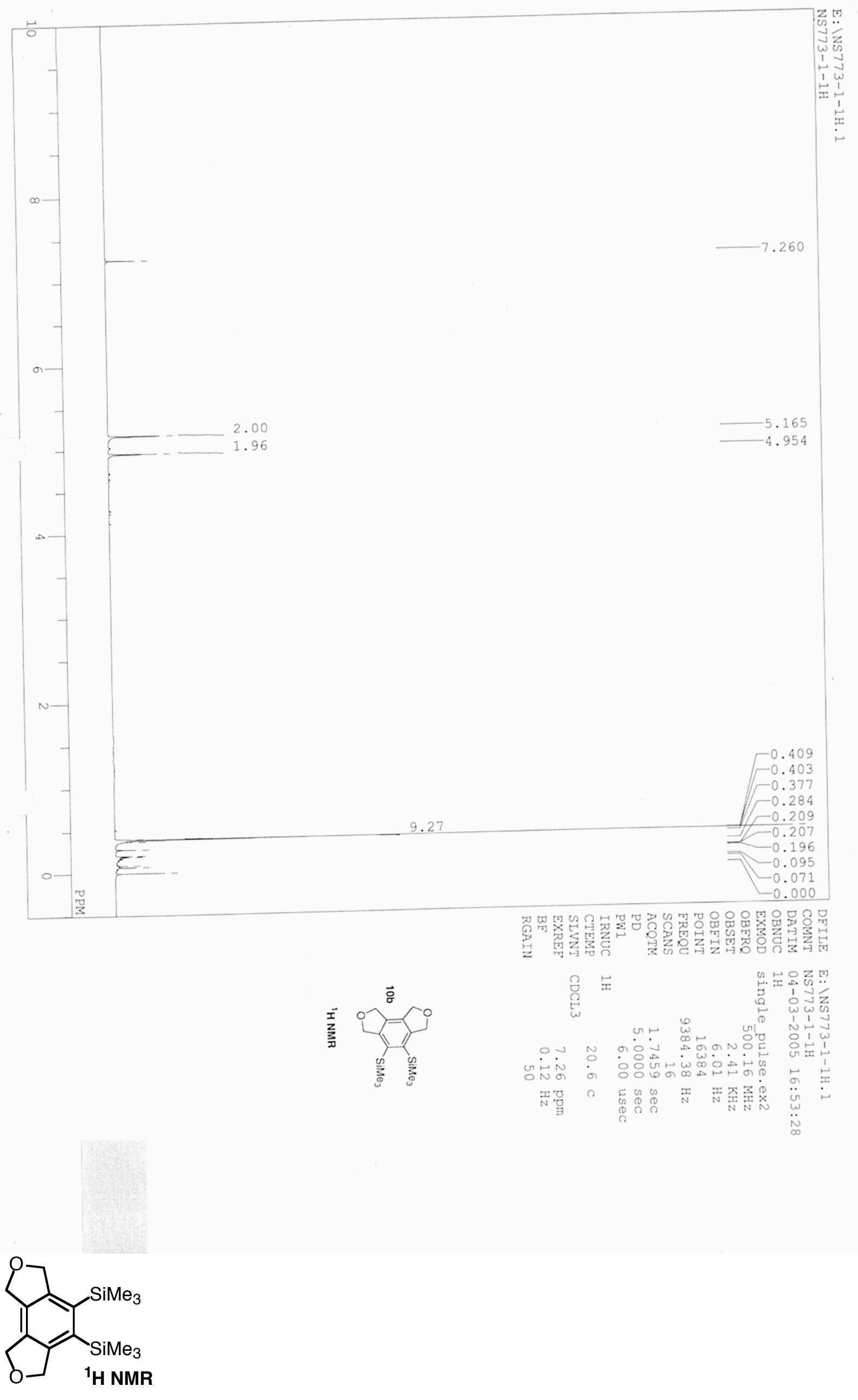

Page: 4 


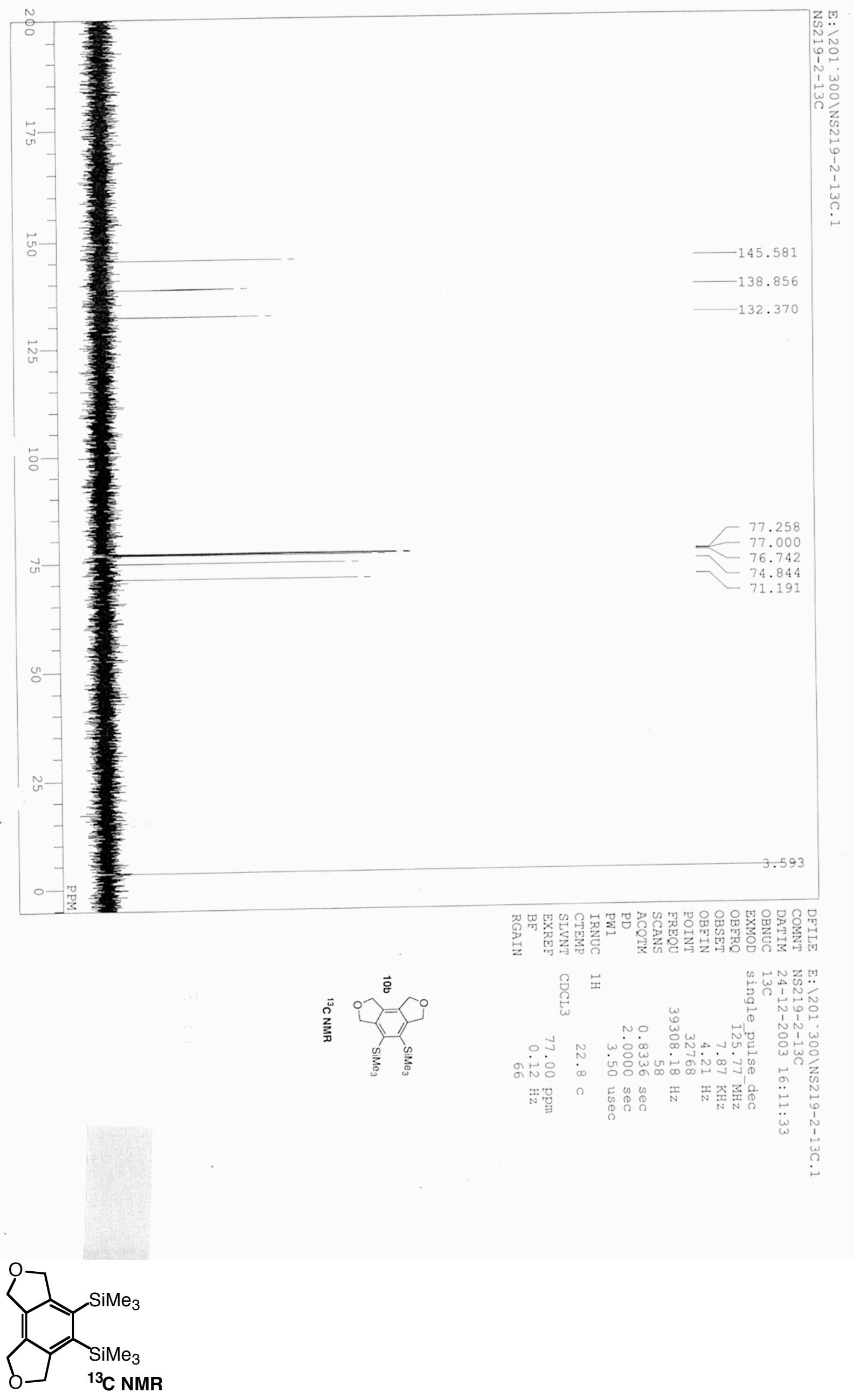

Page: 5 


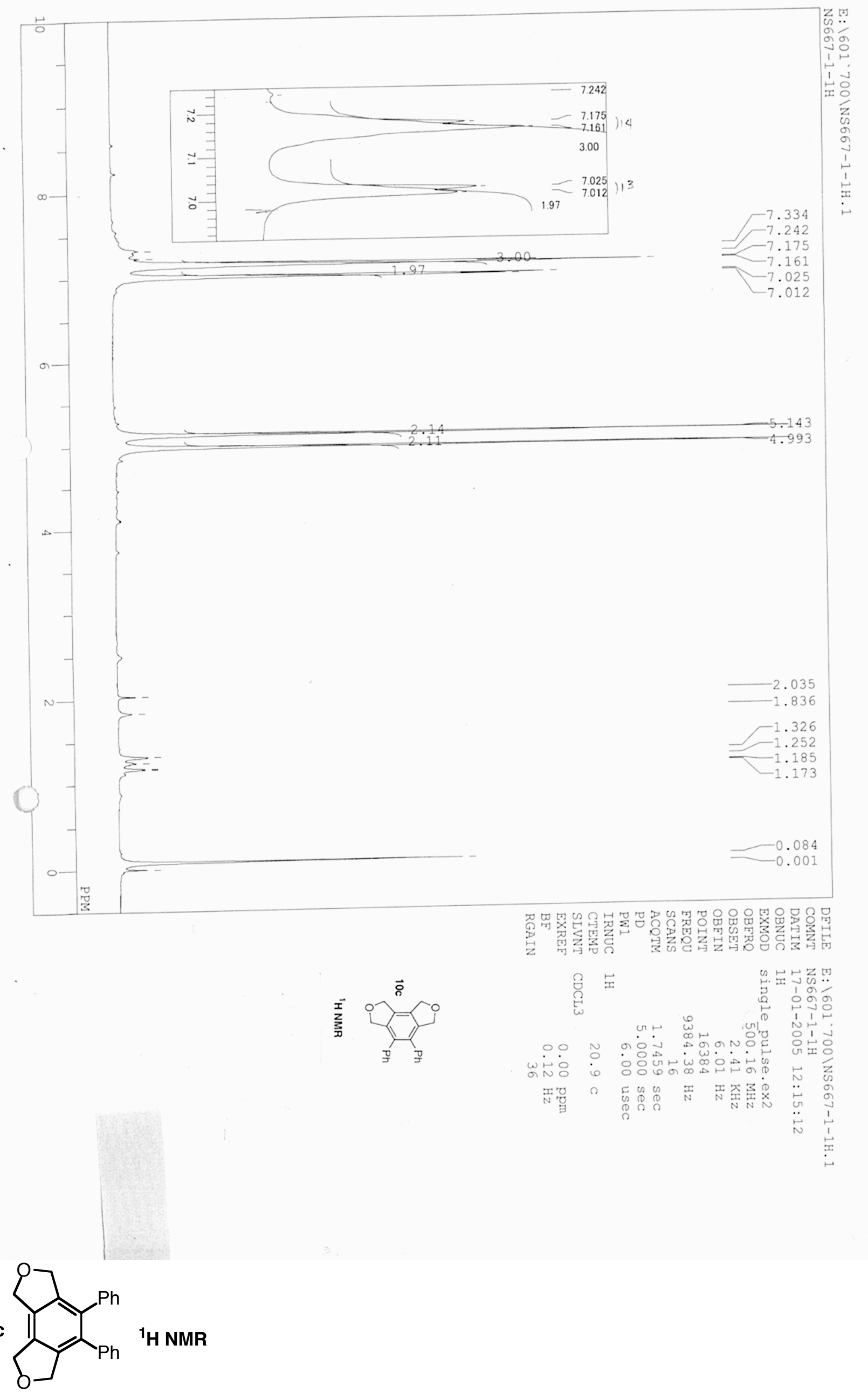

Page: 6 


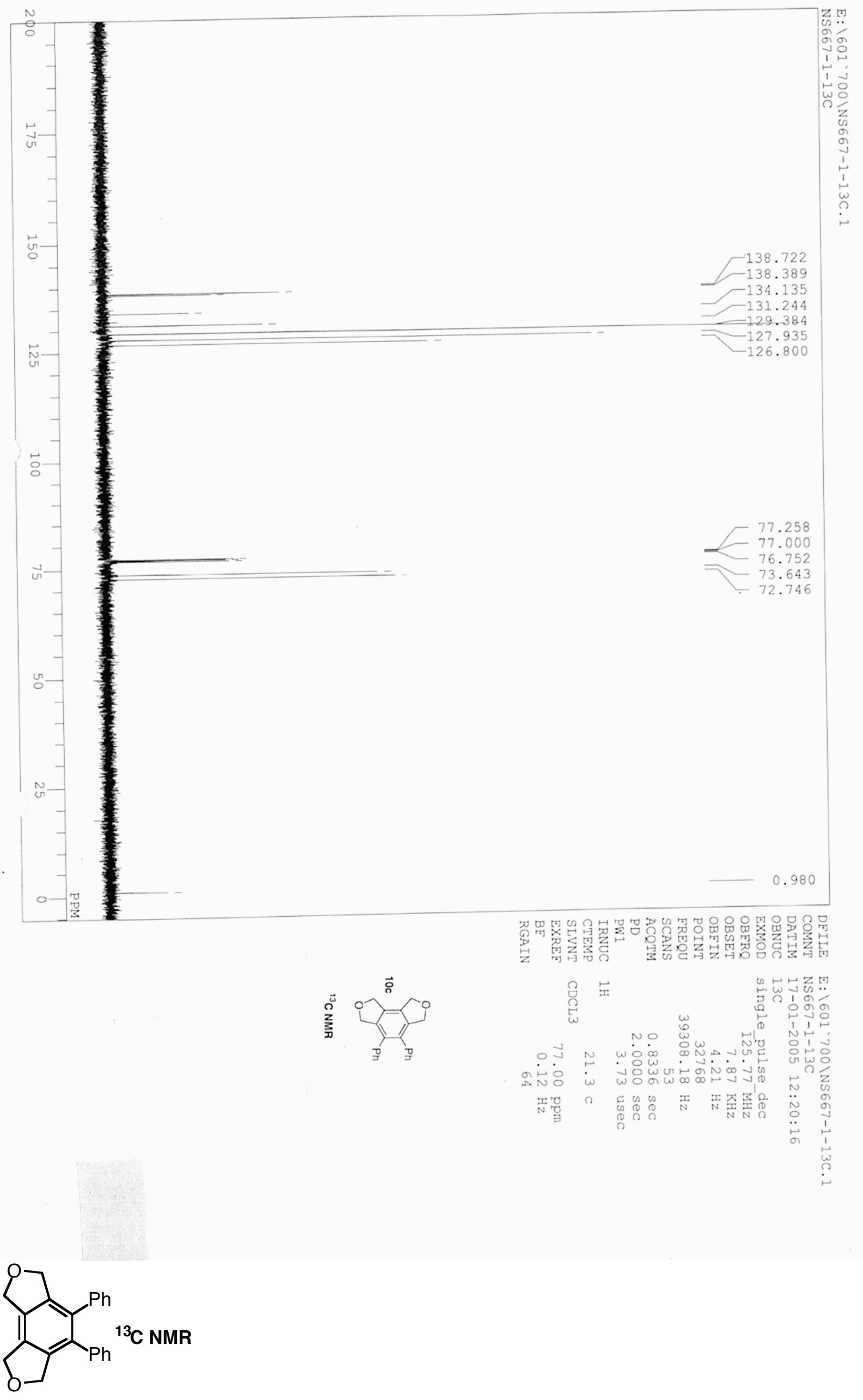



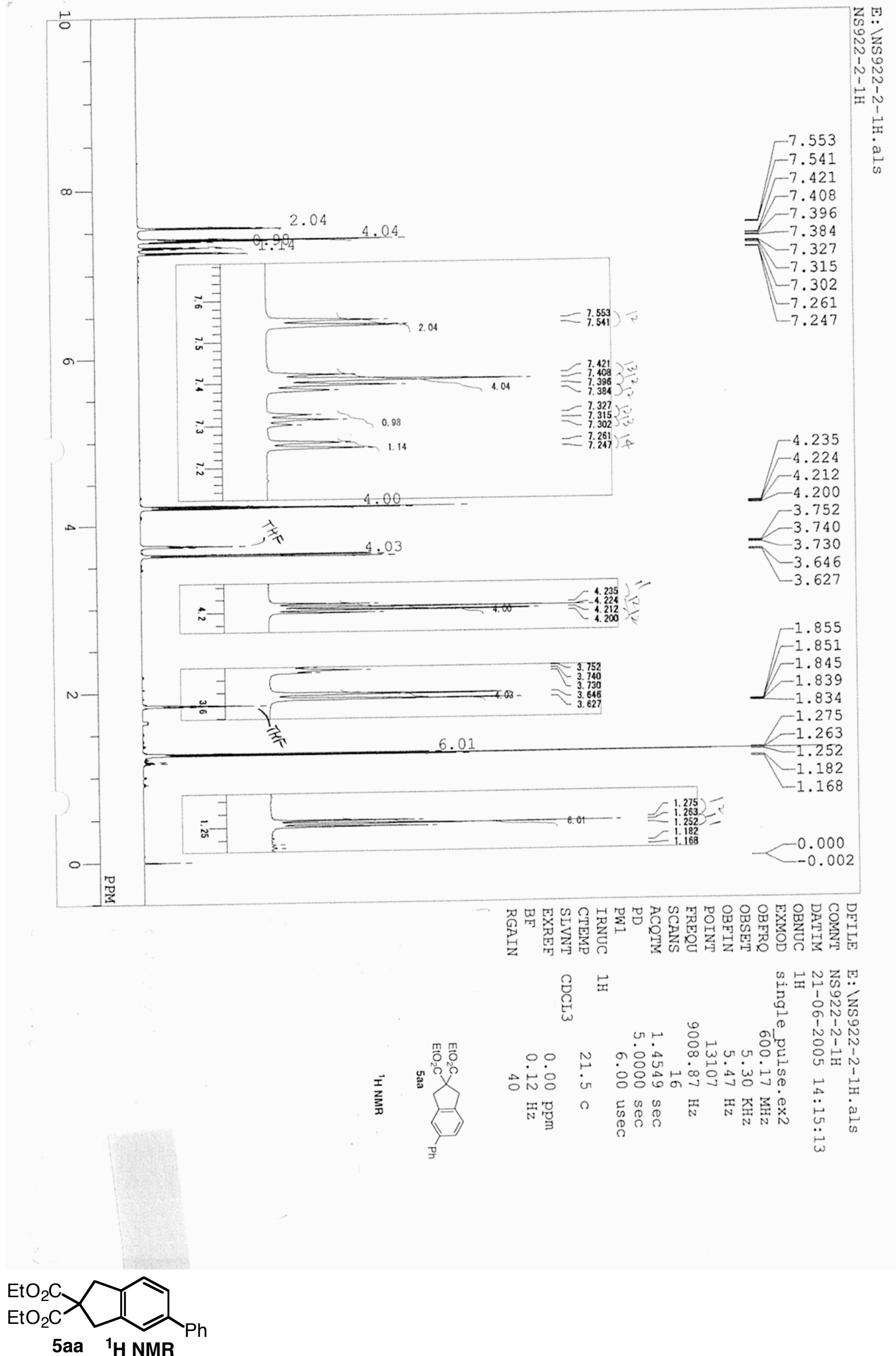

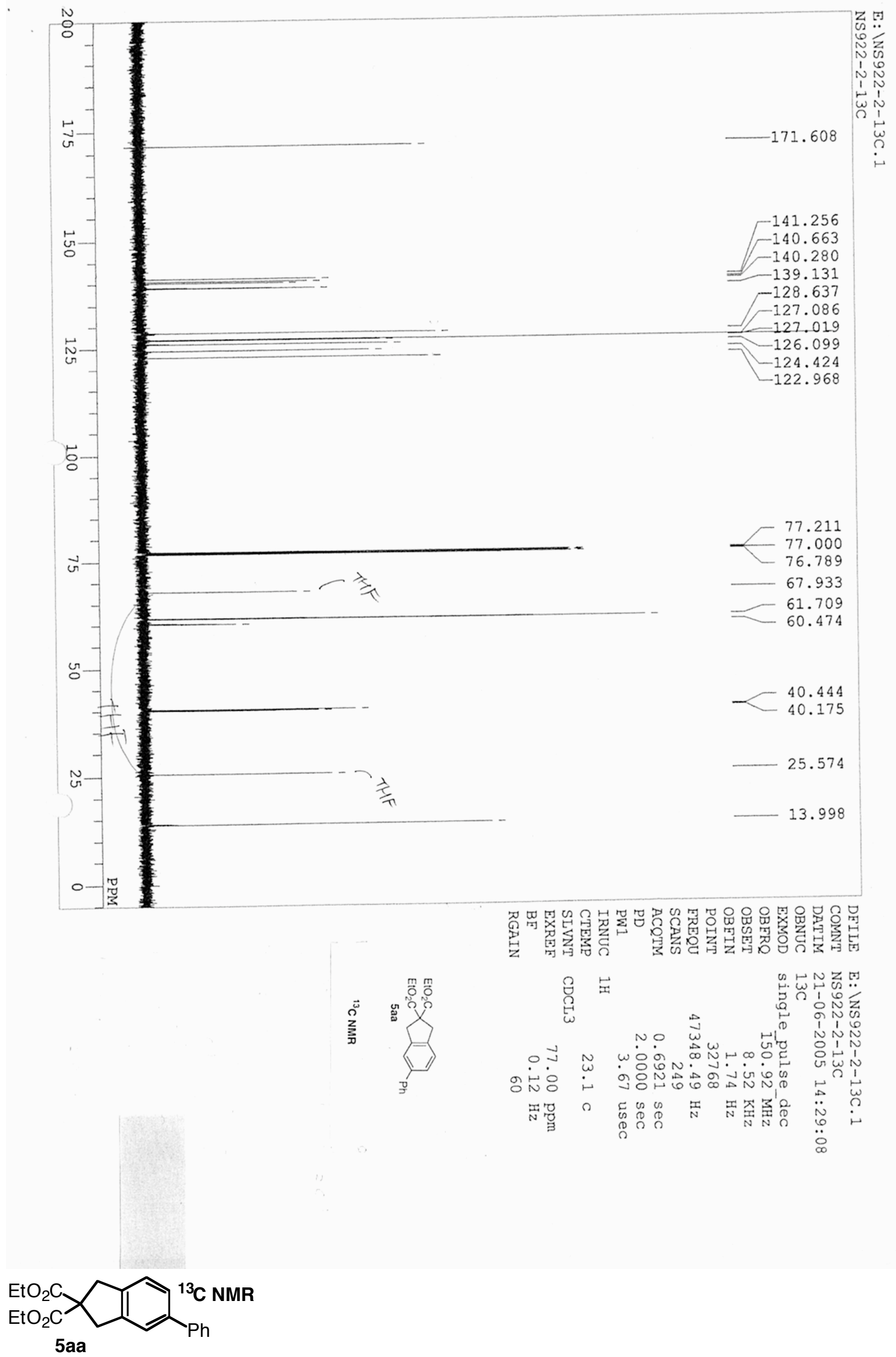

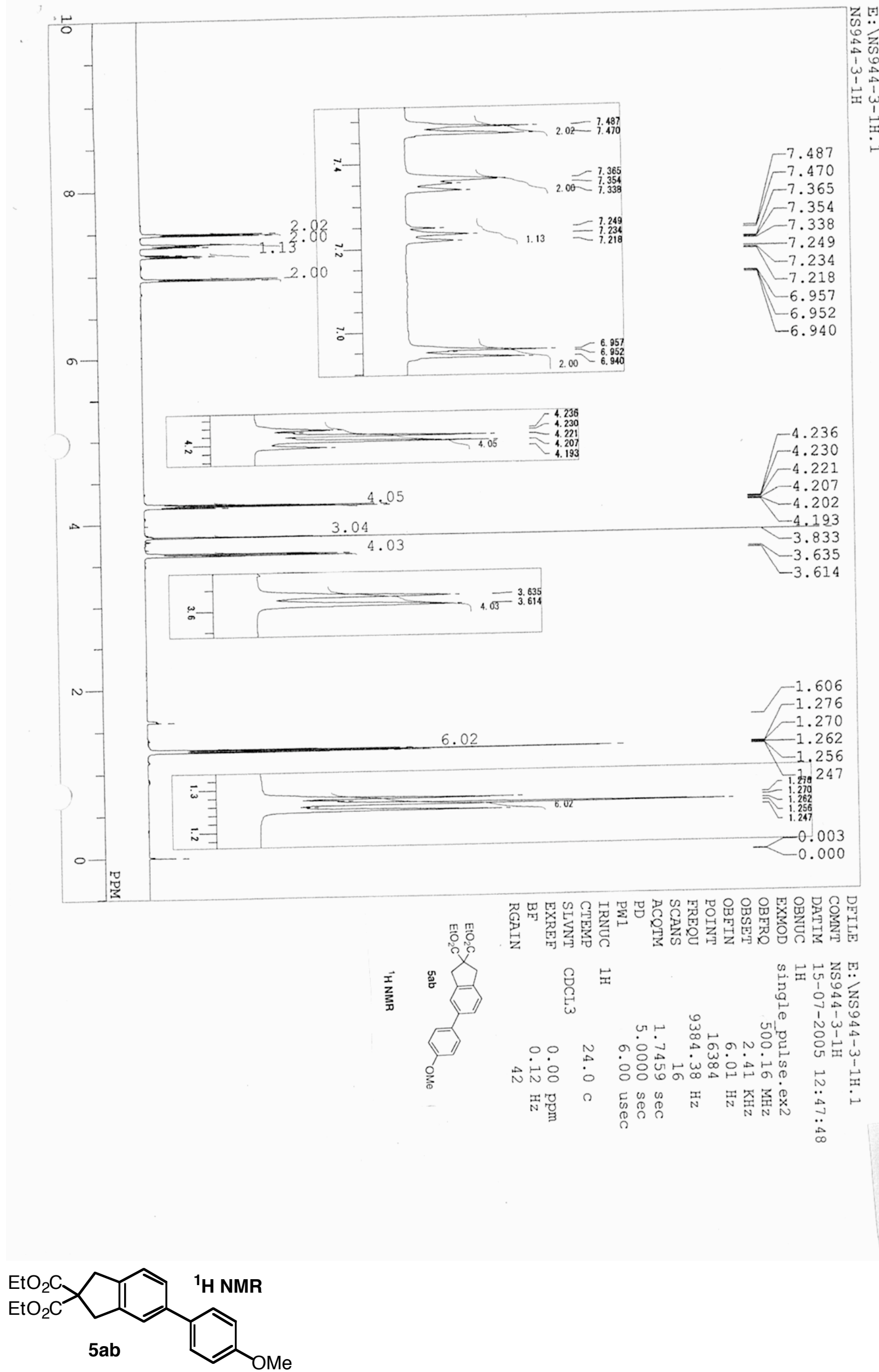

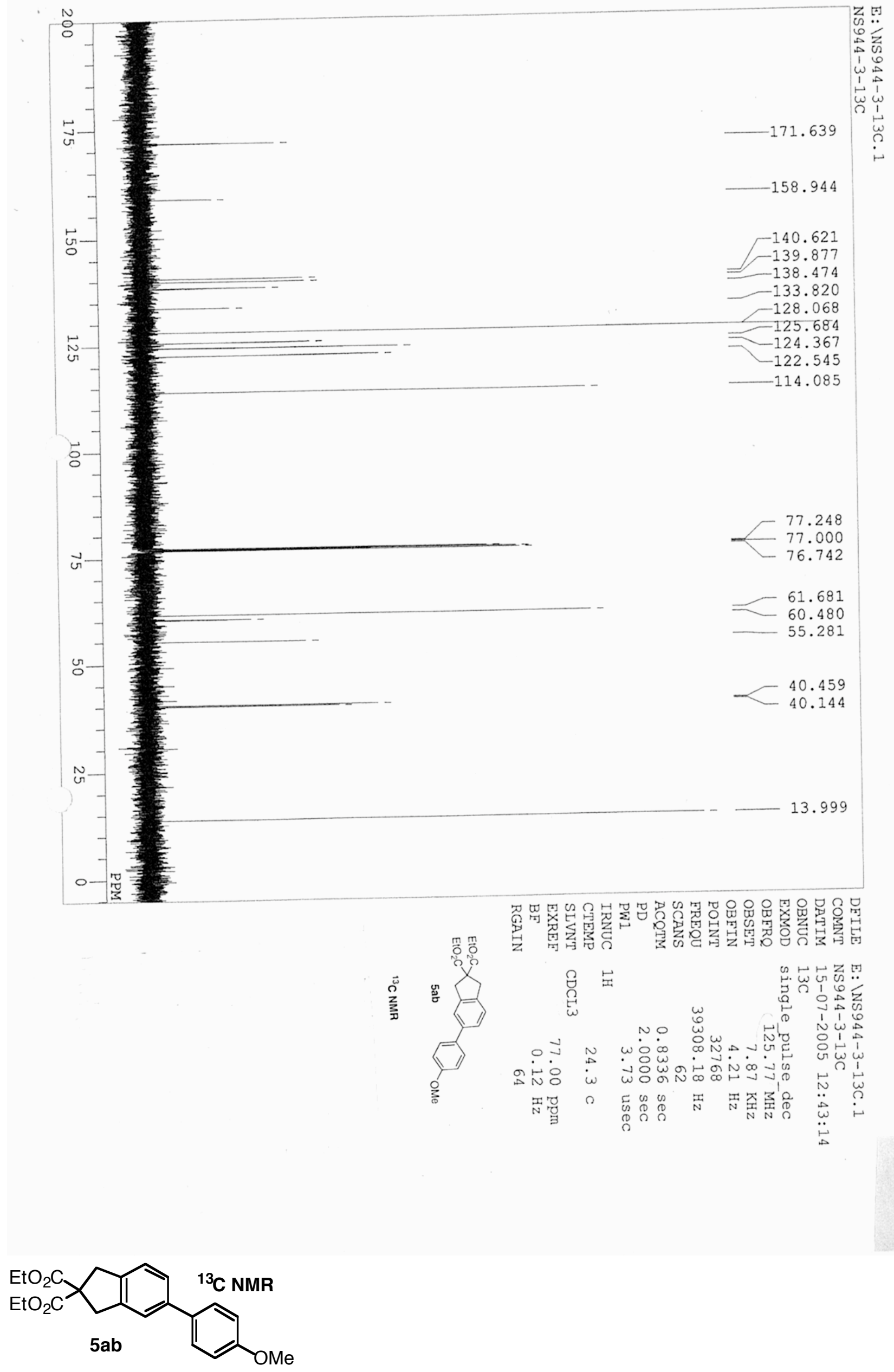

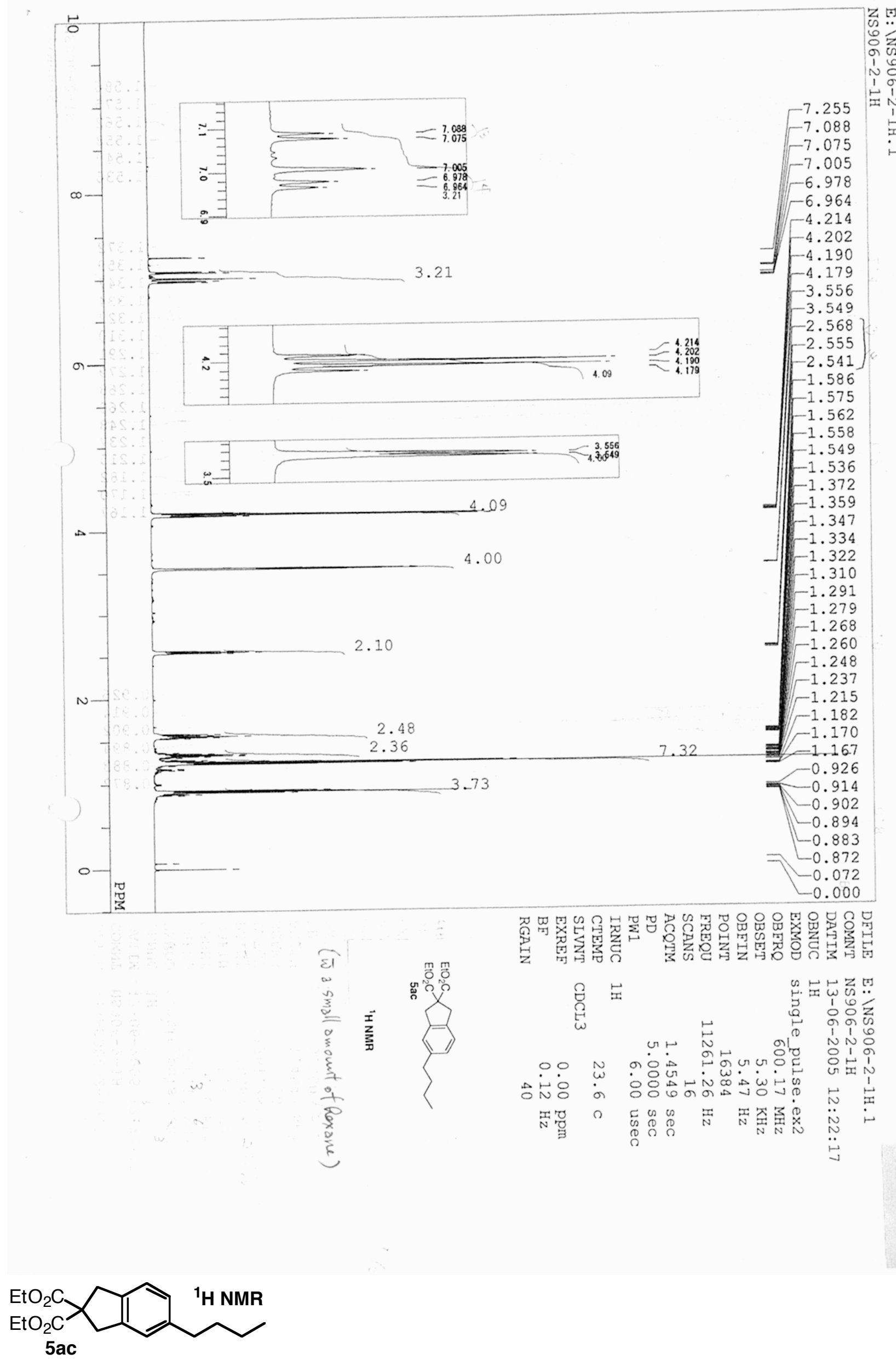

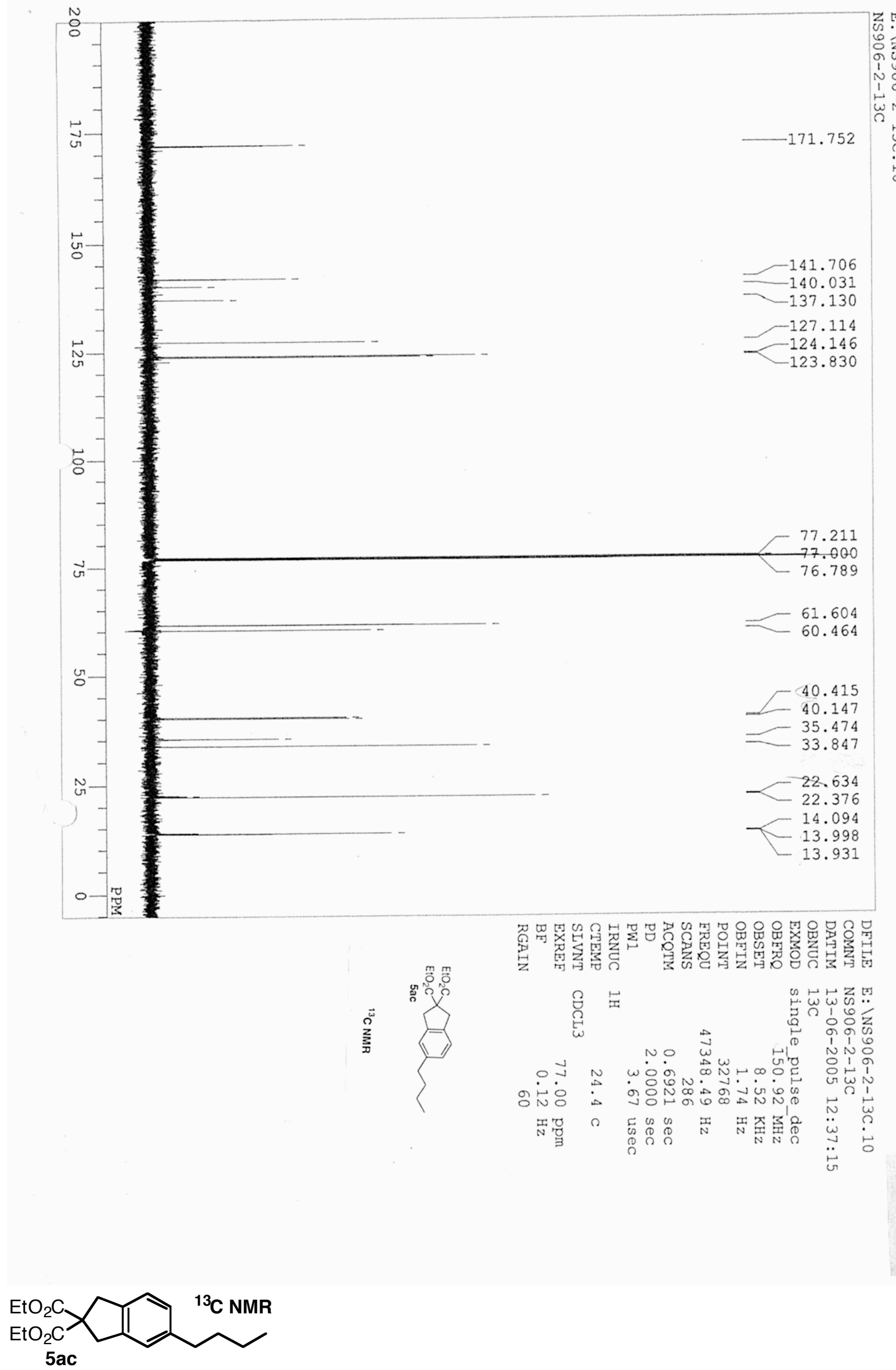

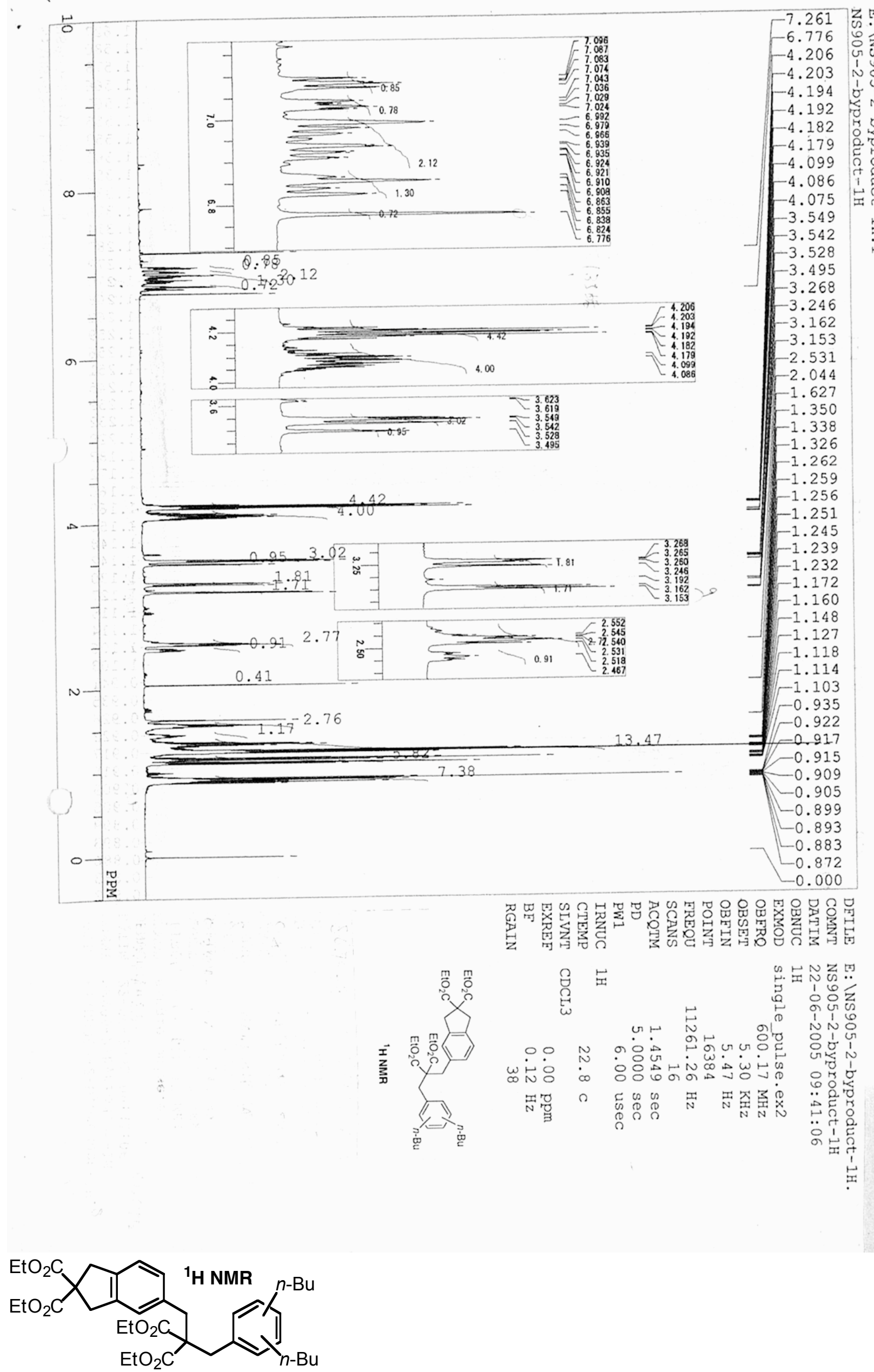

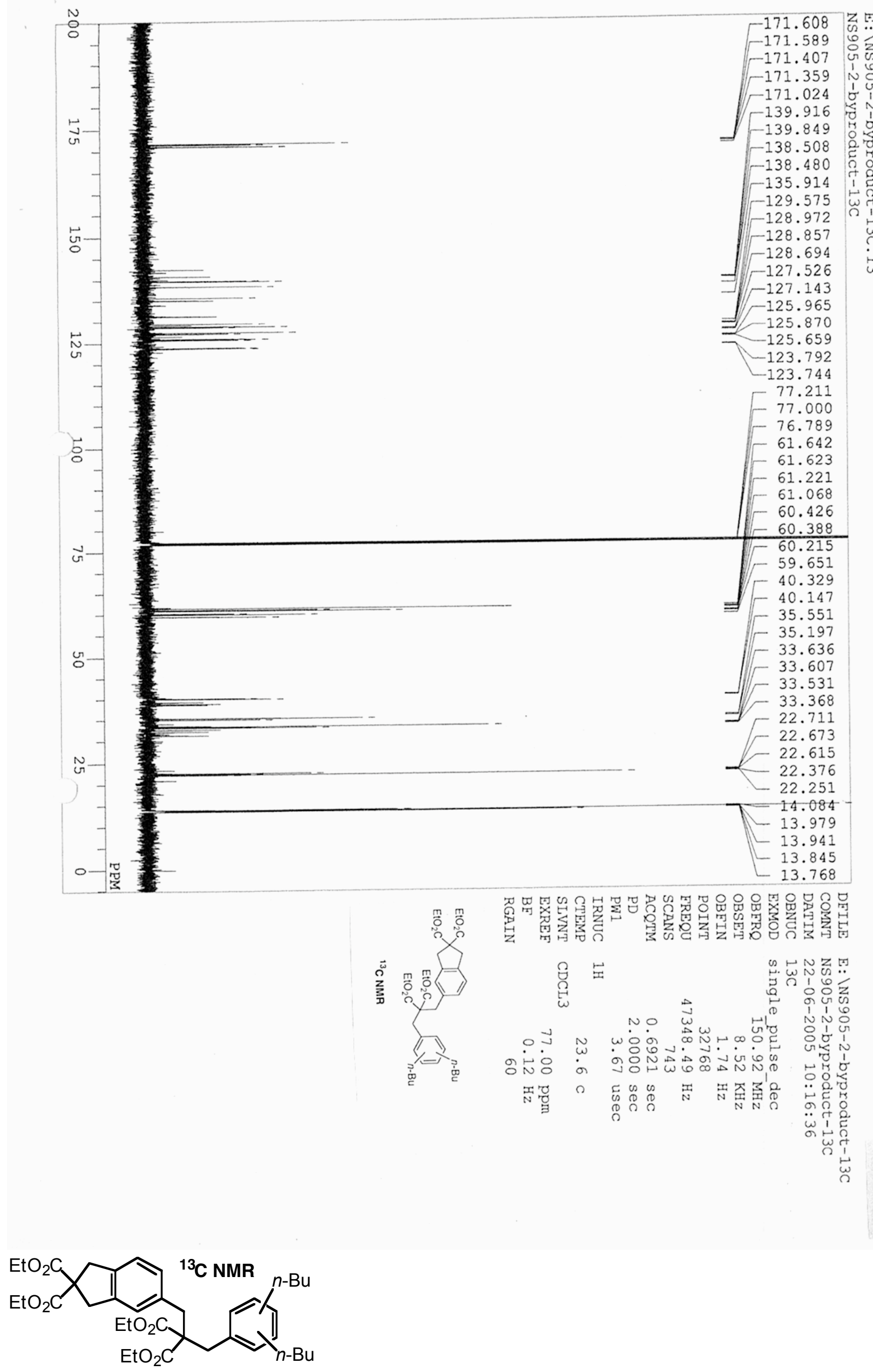

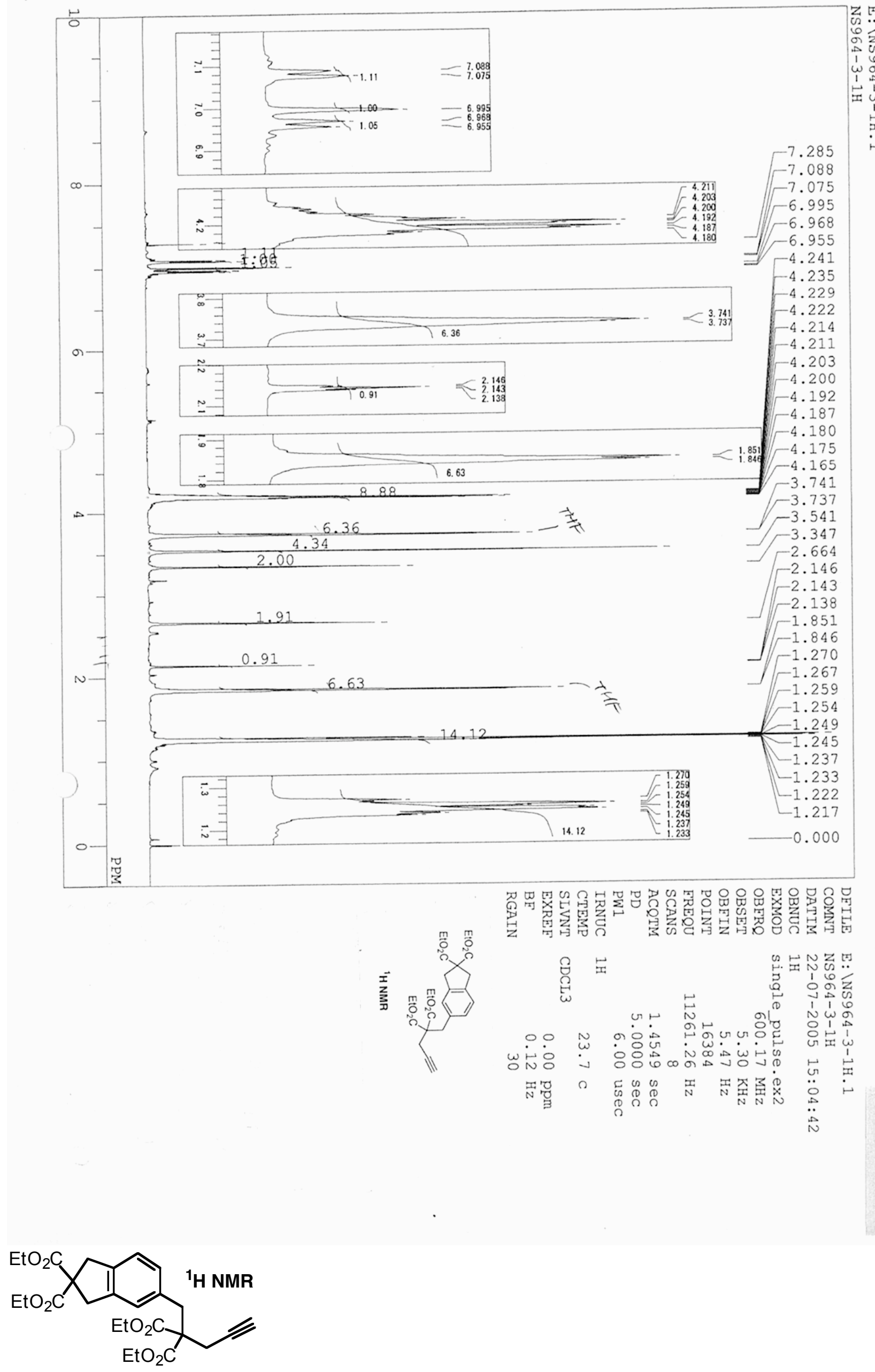

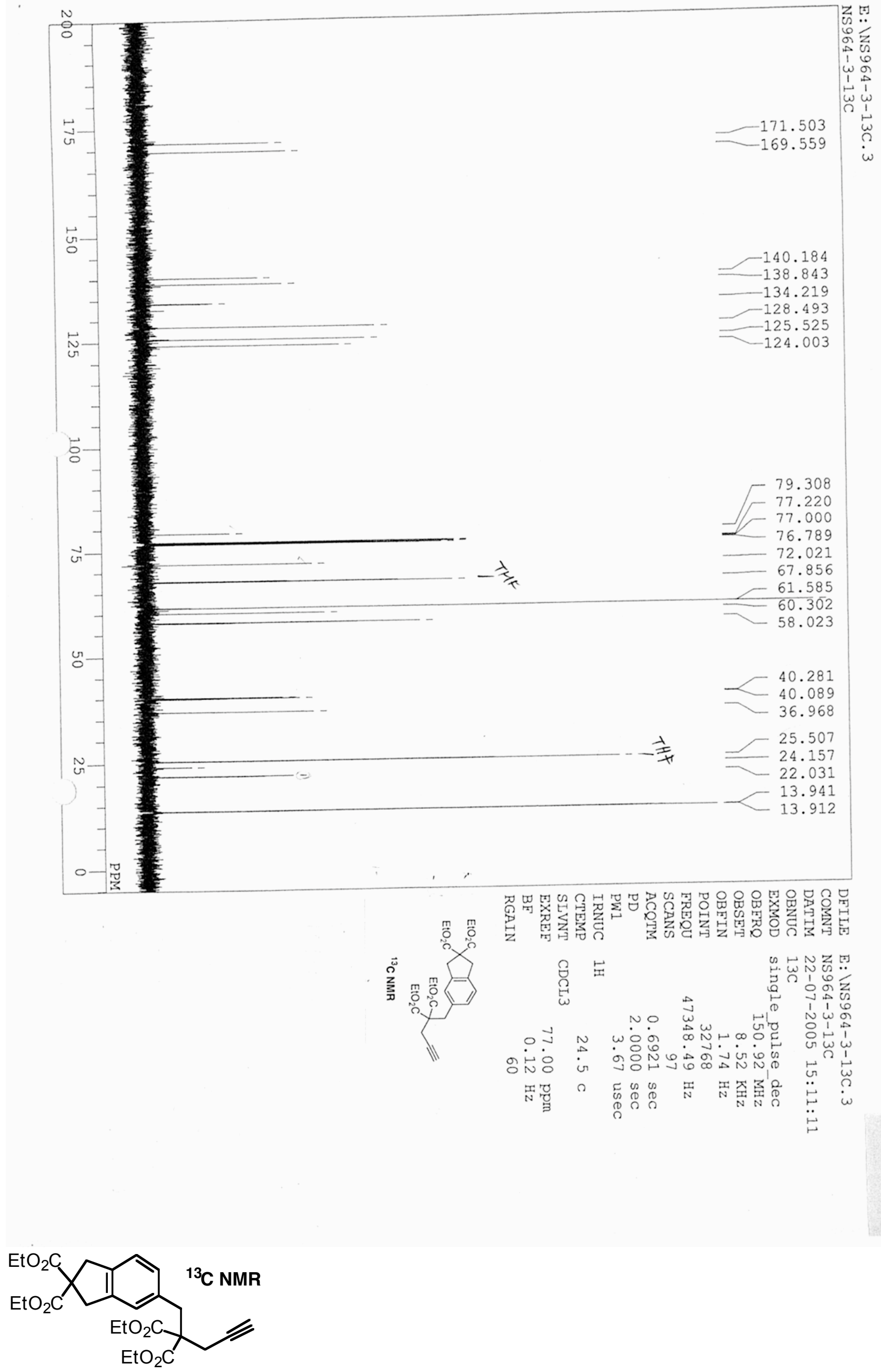

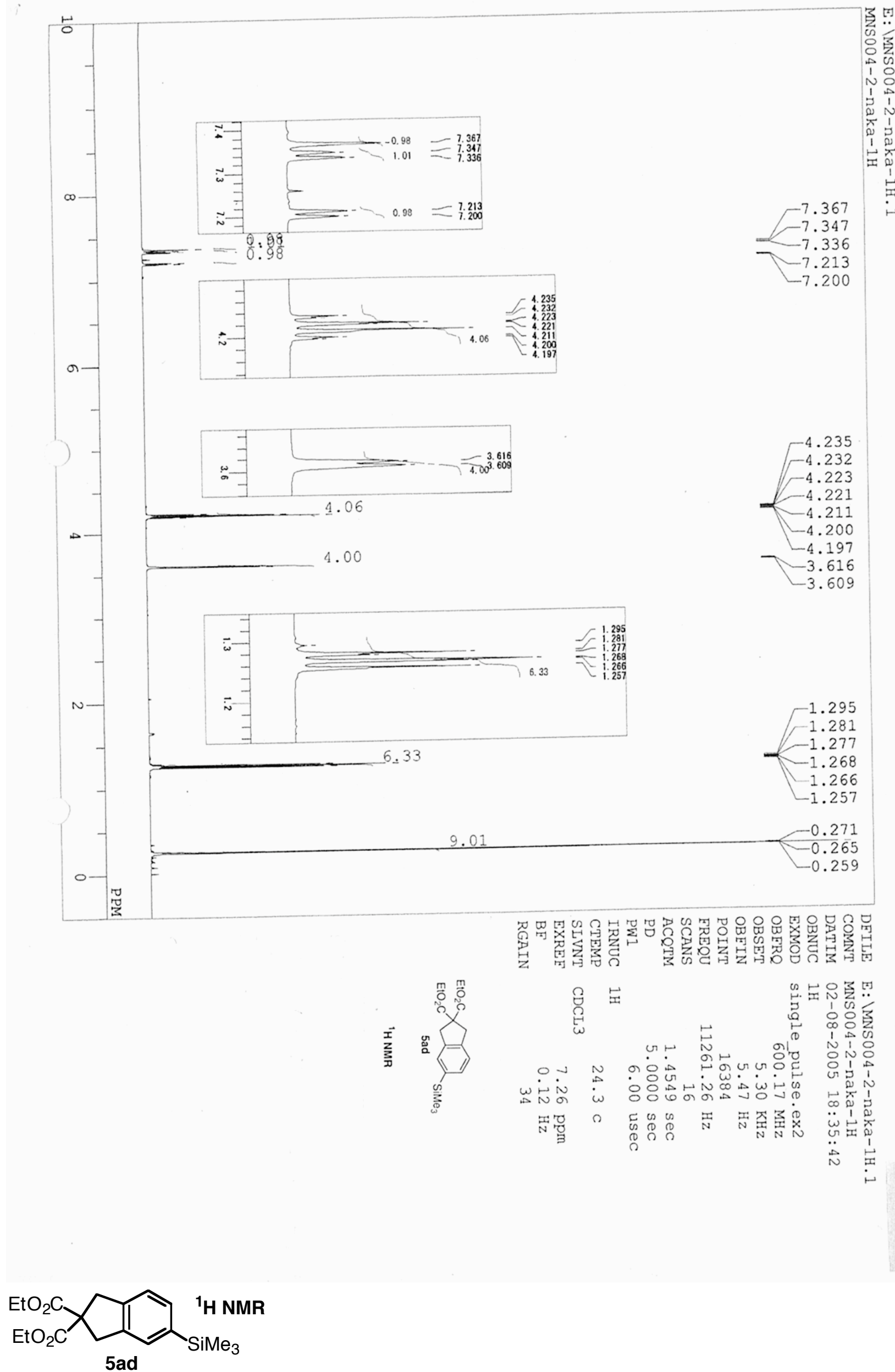

Page: 18 

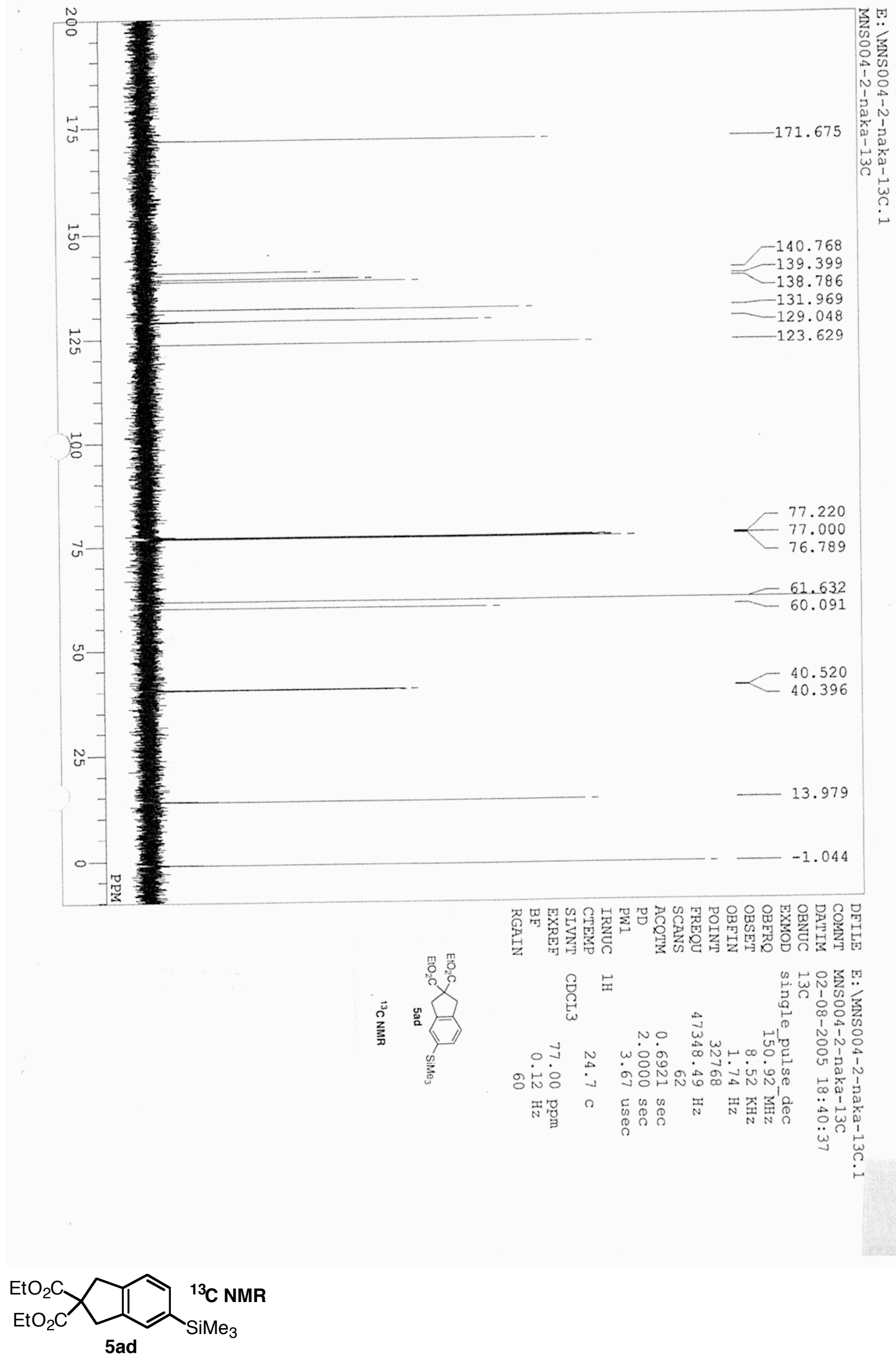


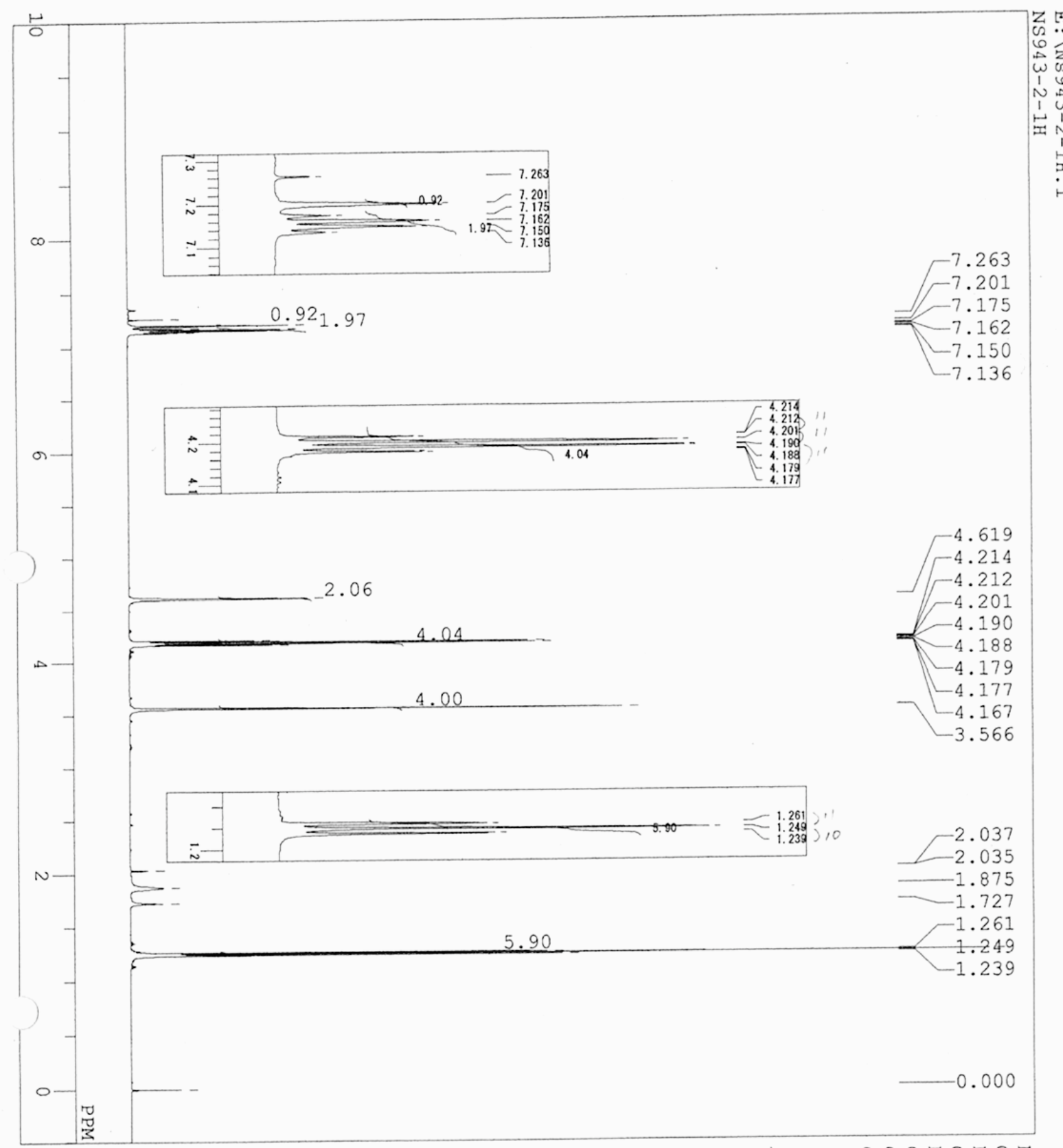

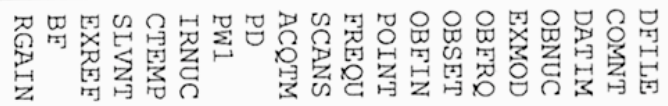

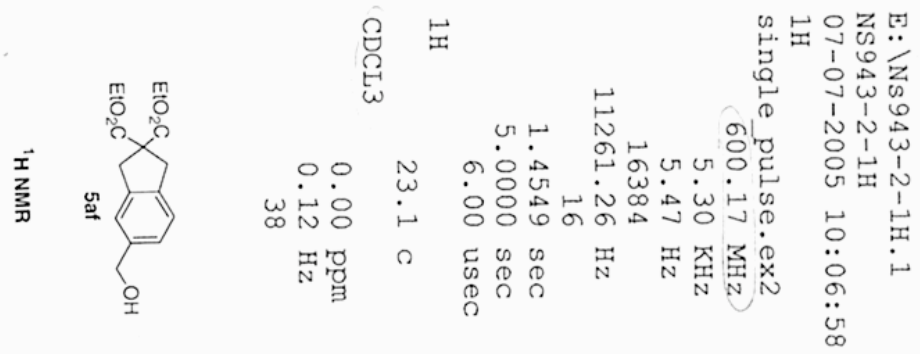

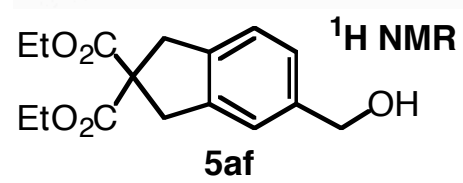



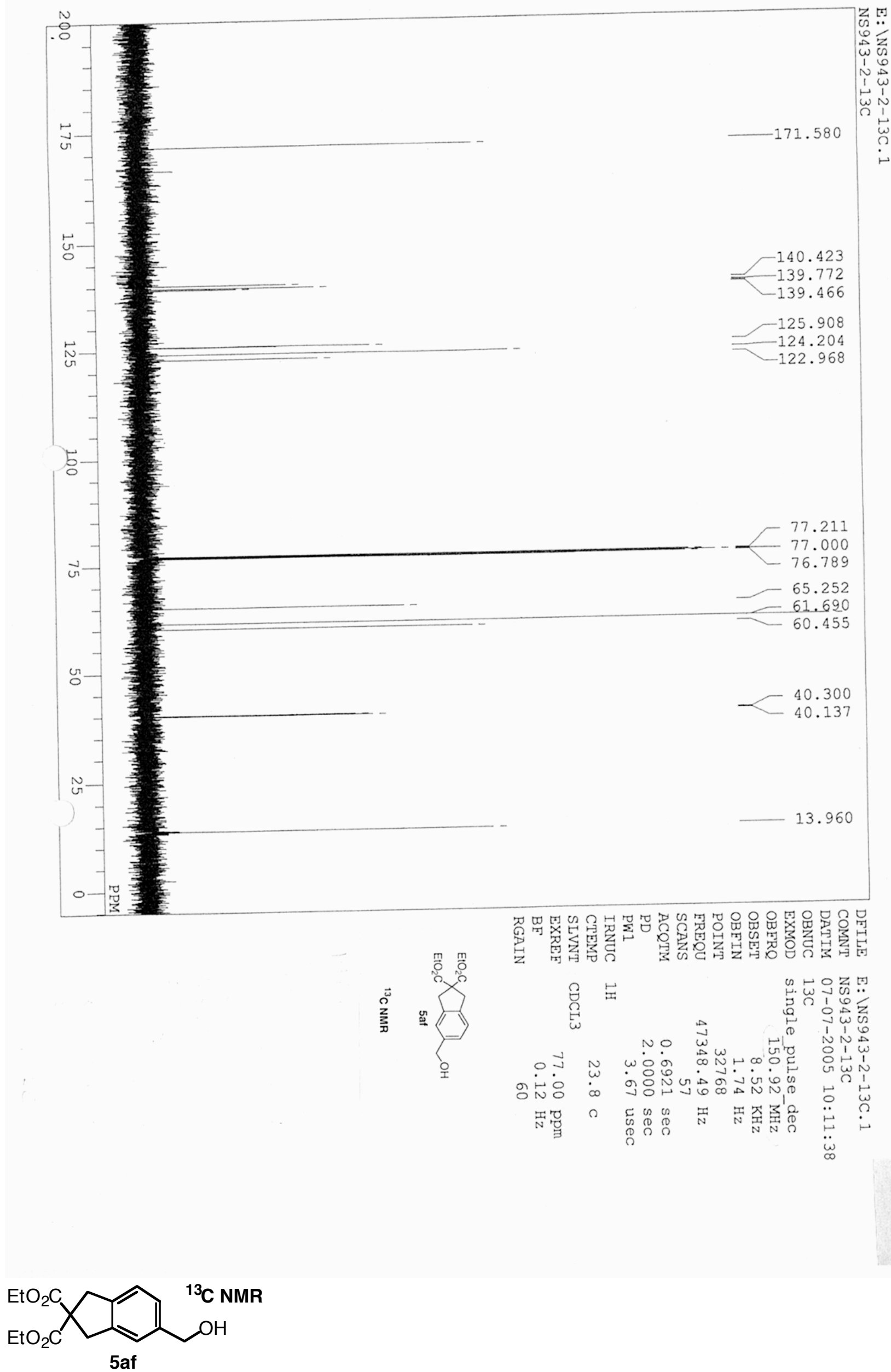

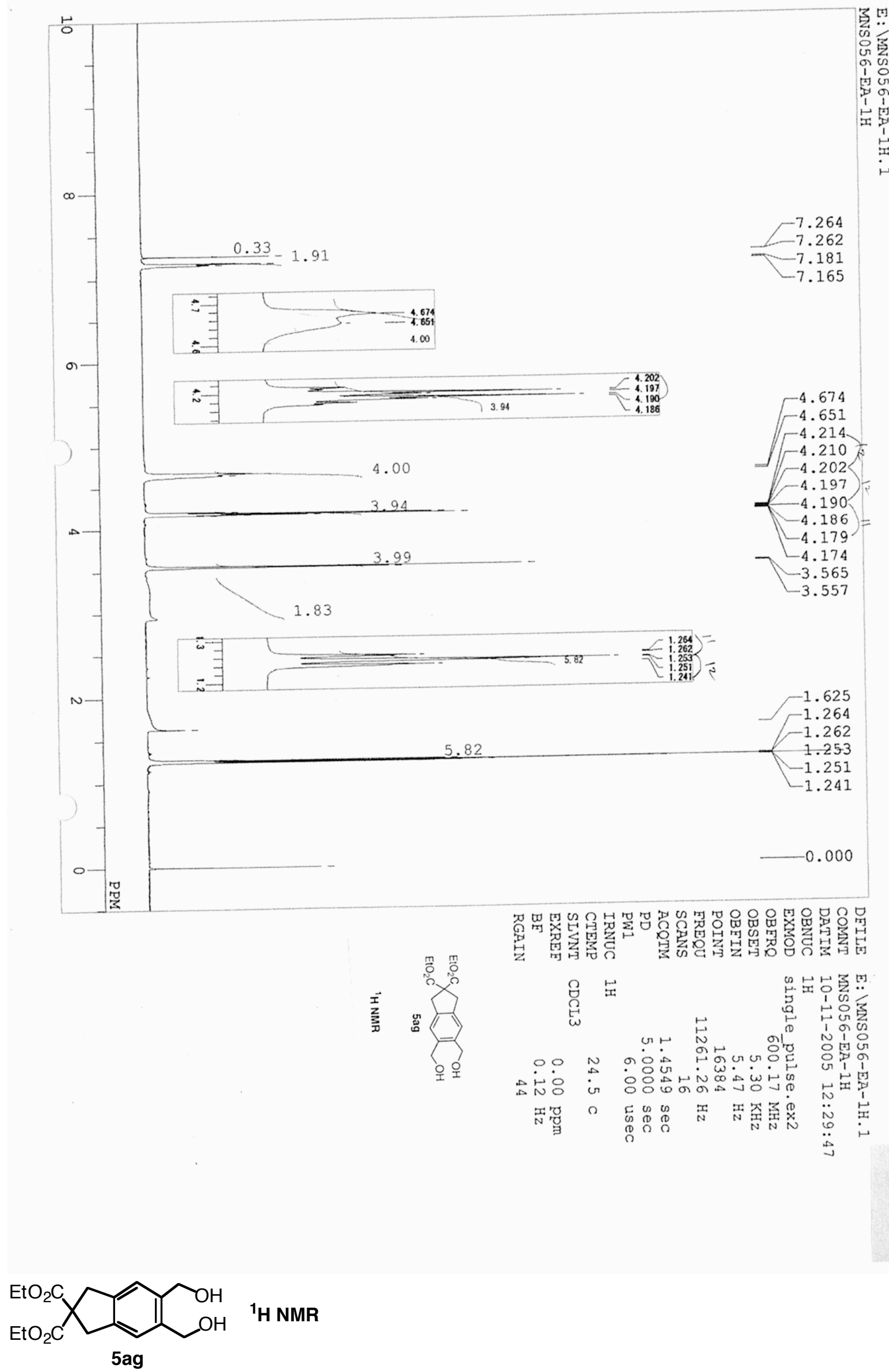

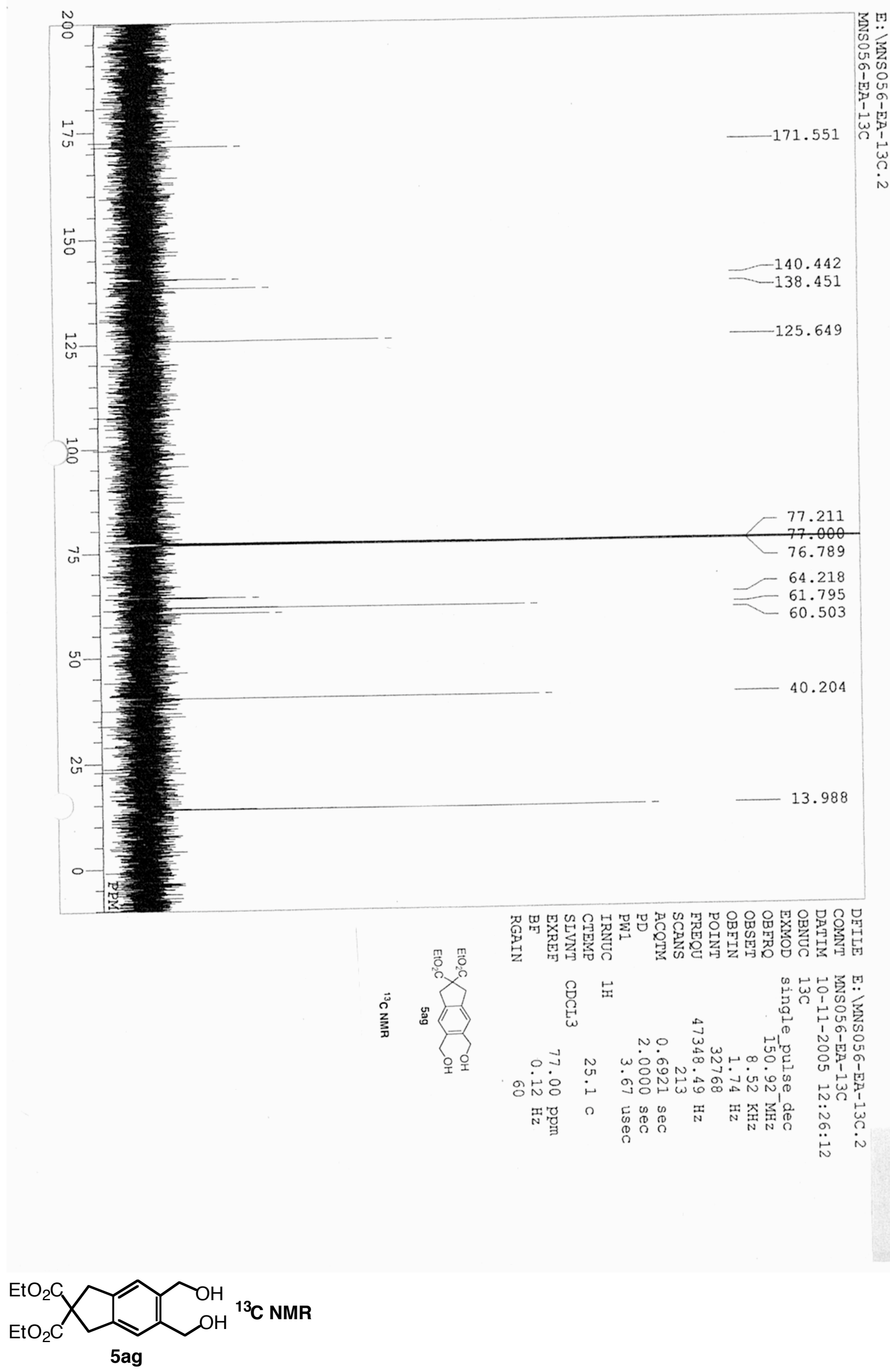


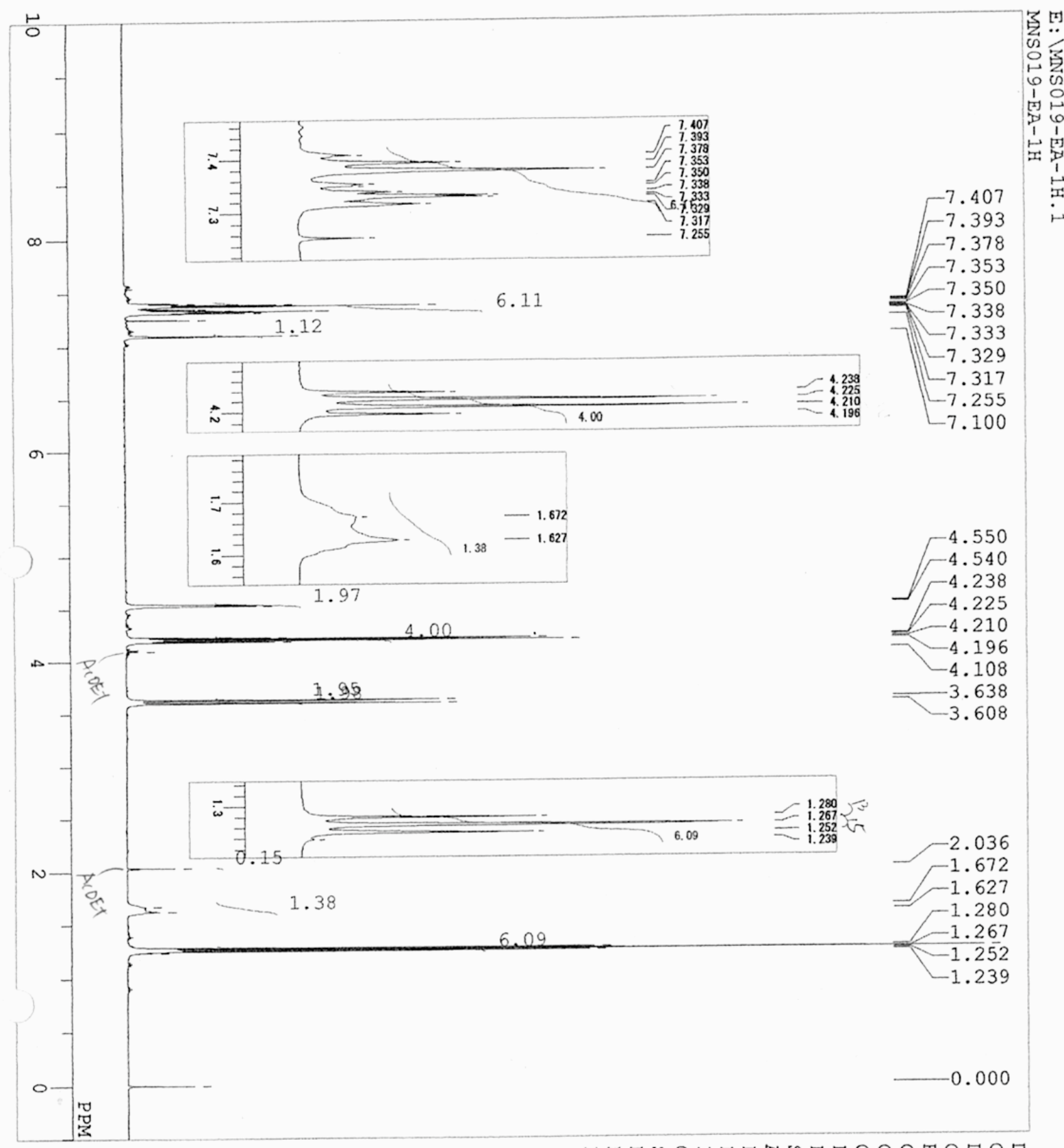

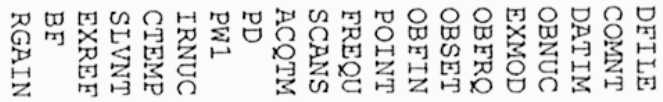
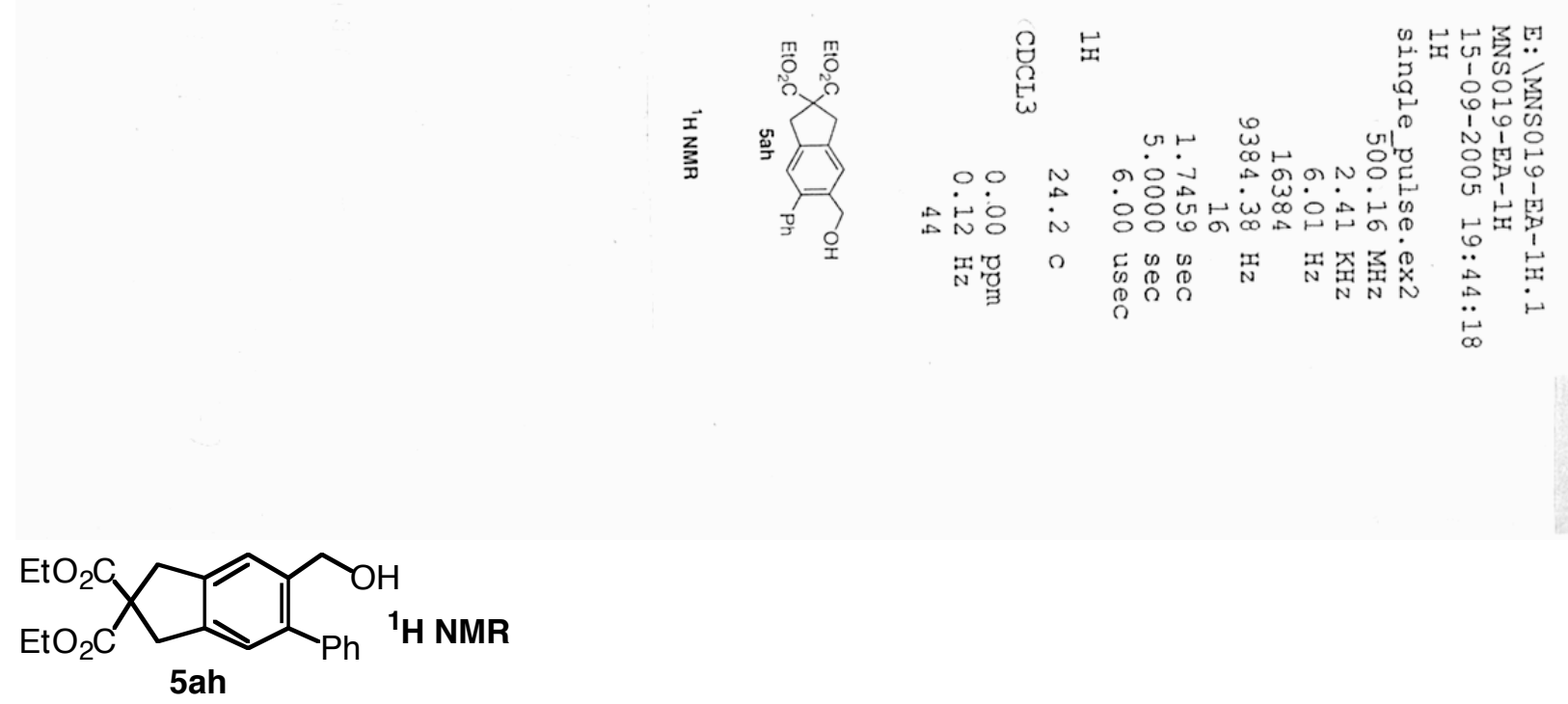

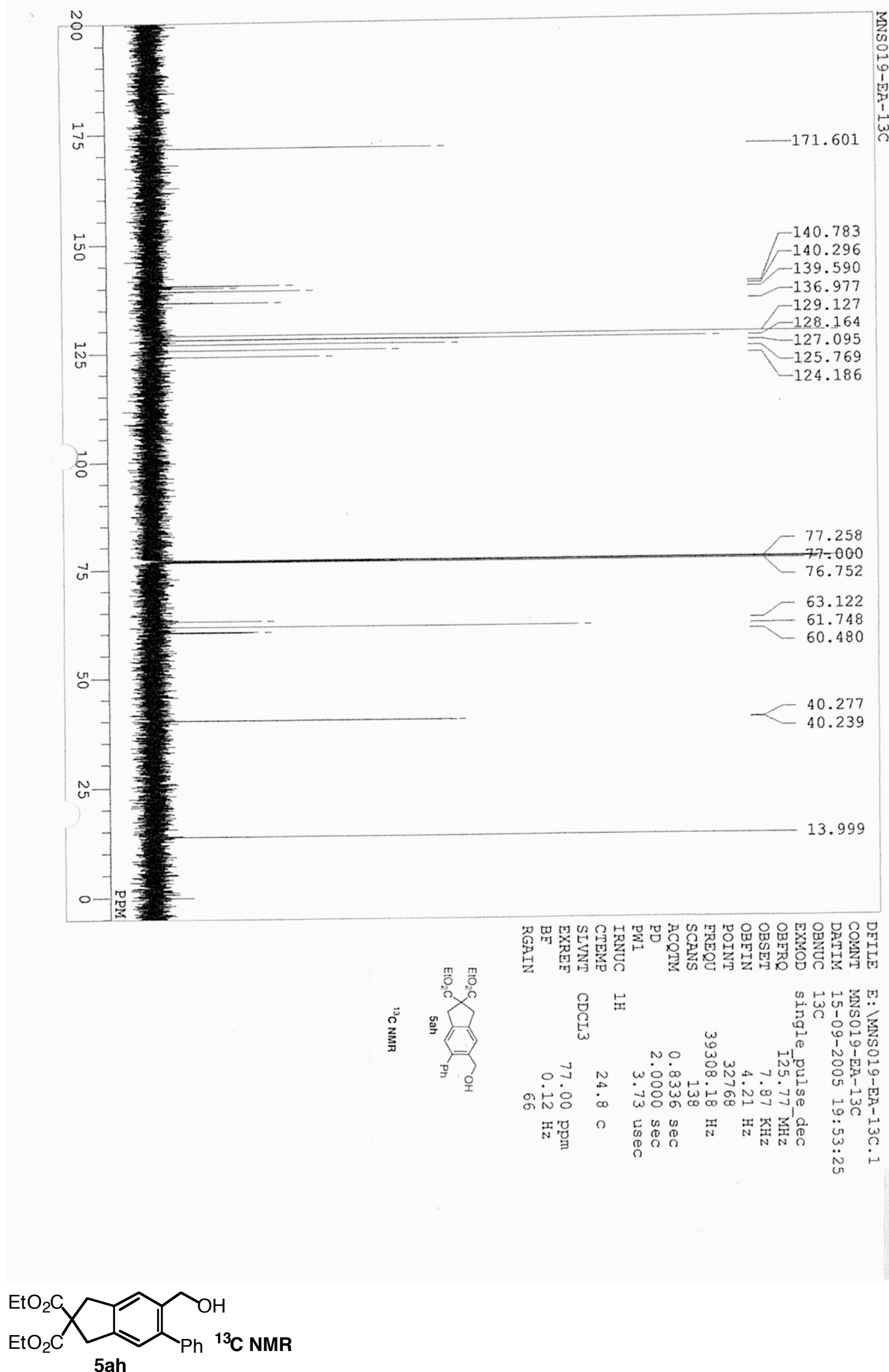

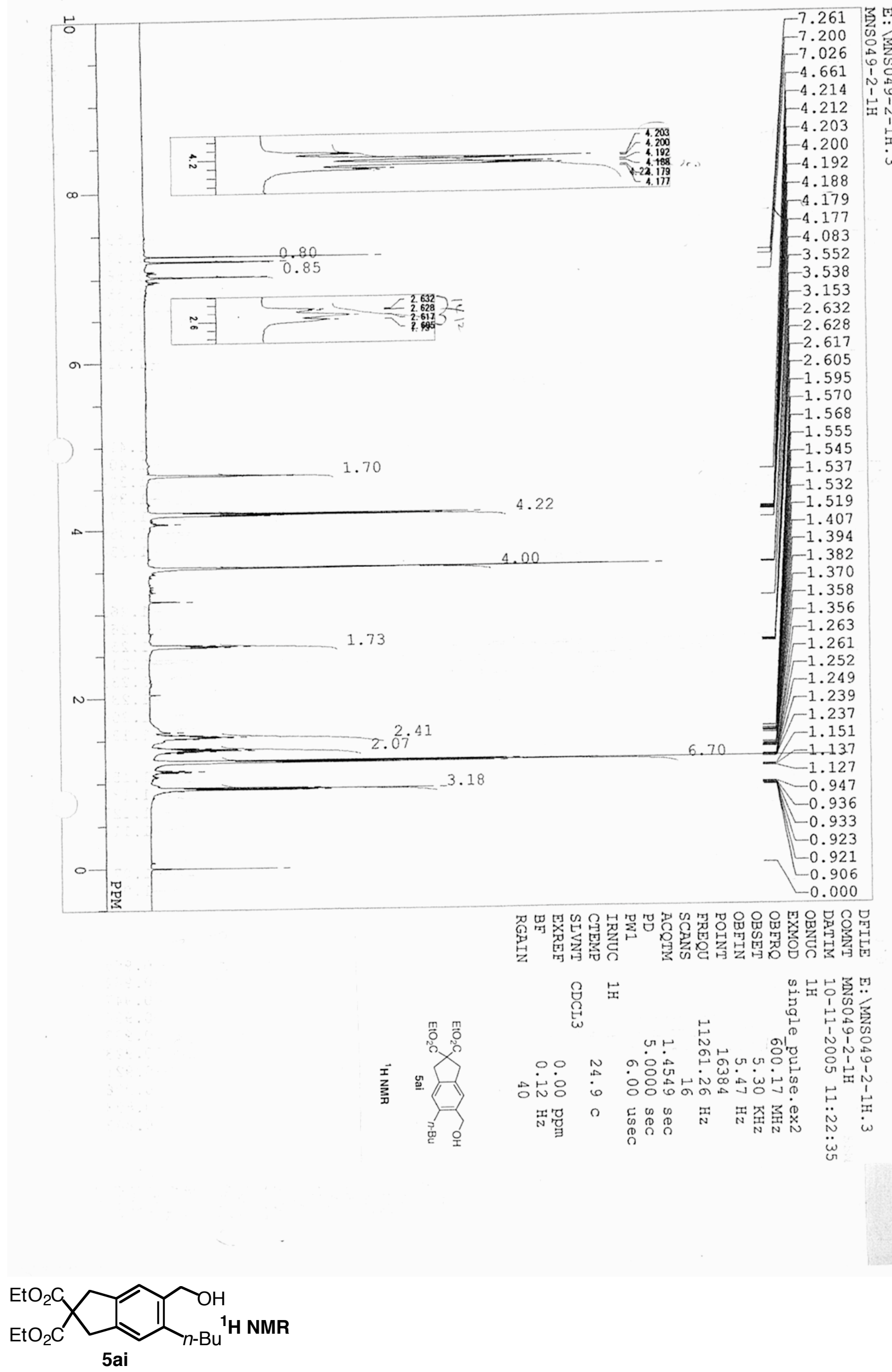

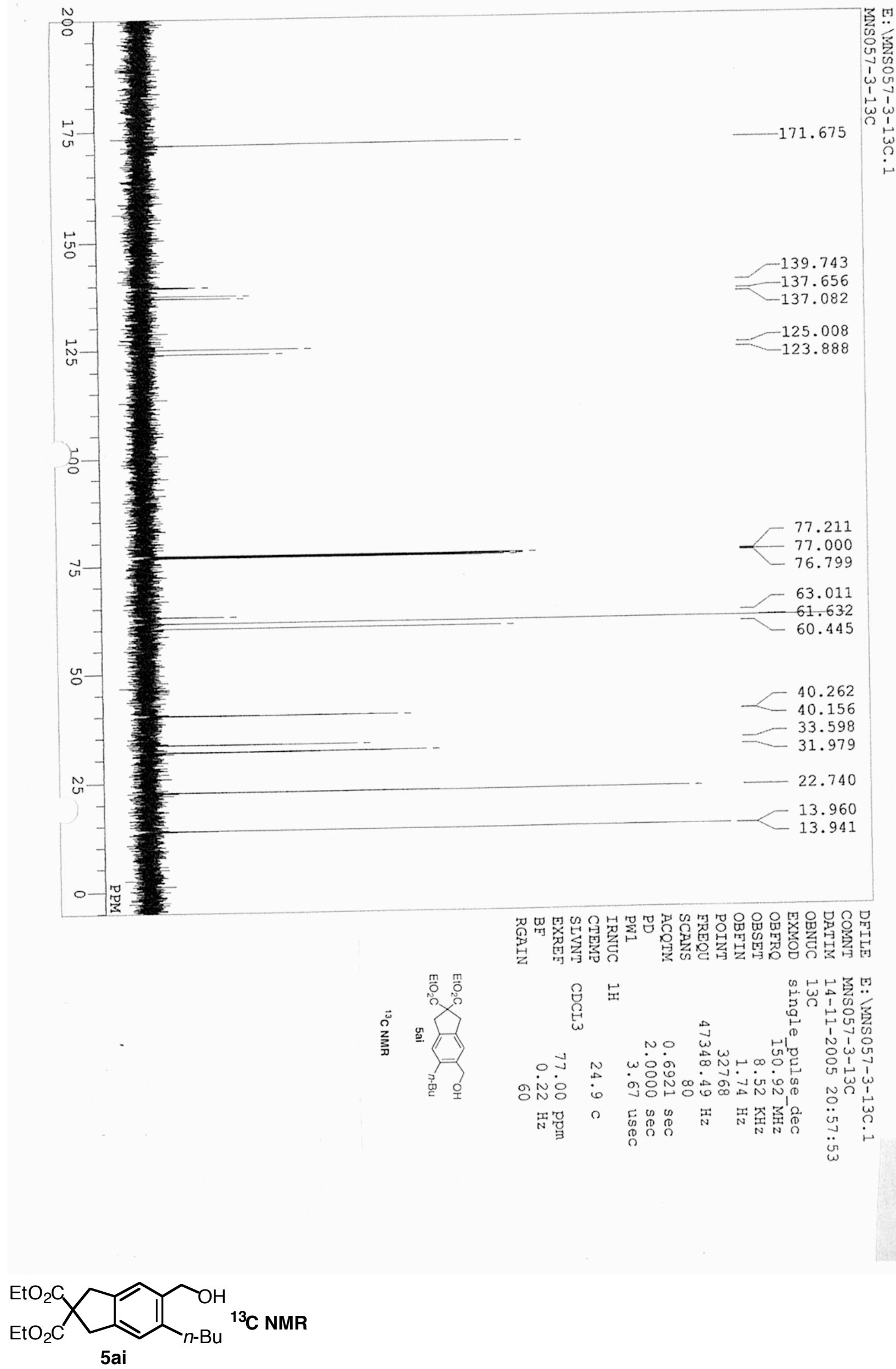

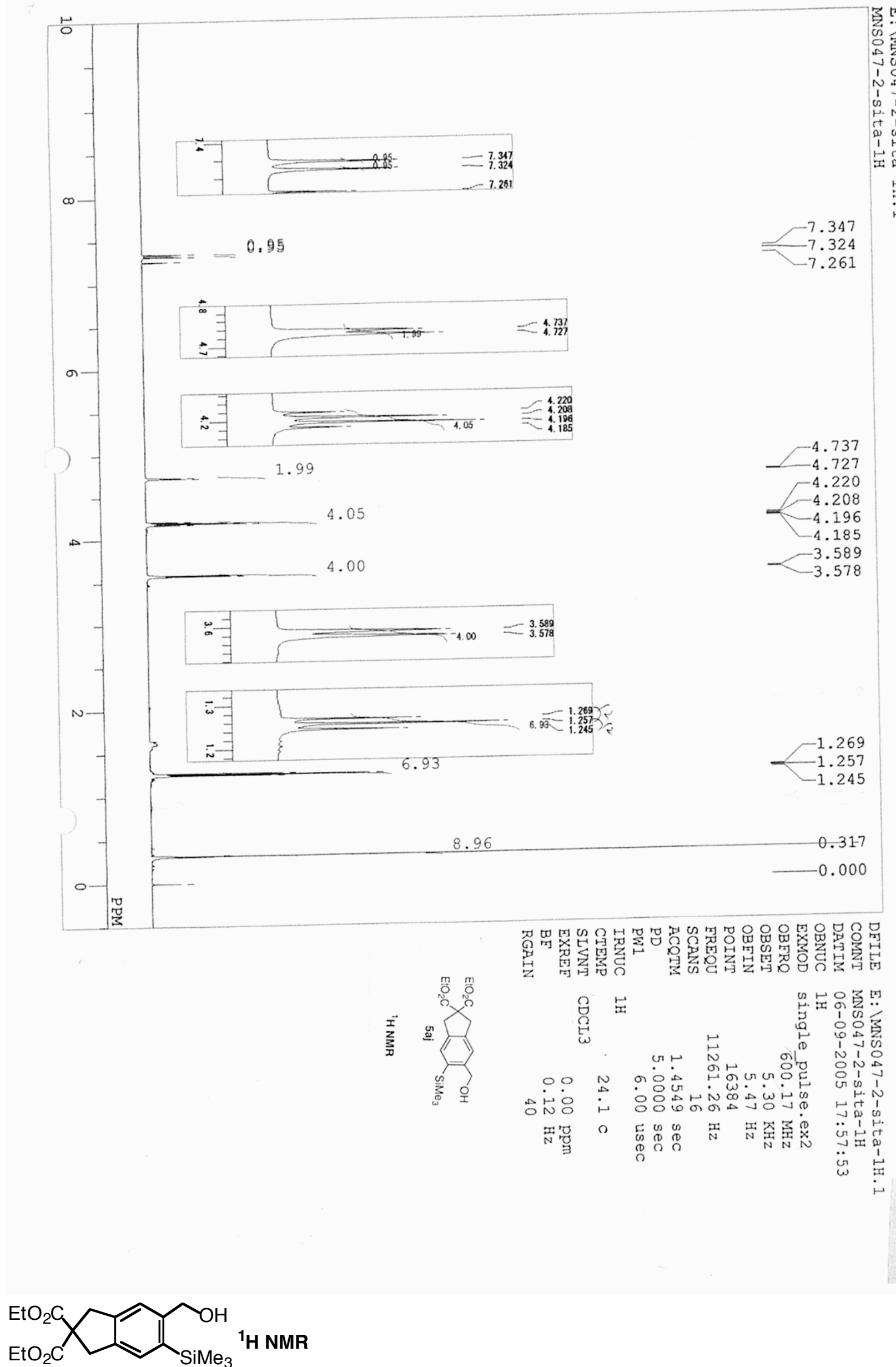

5aj 

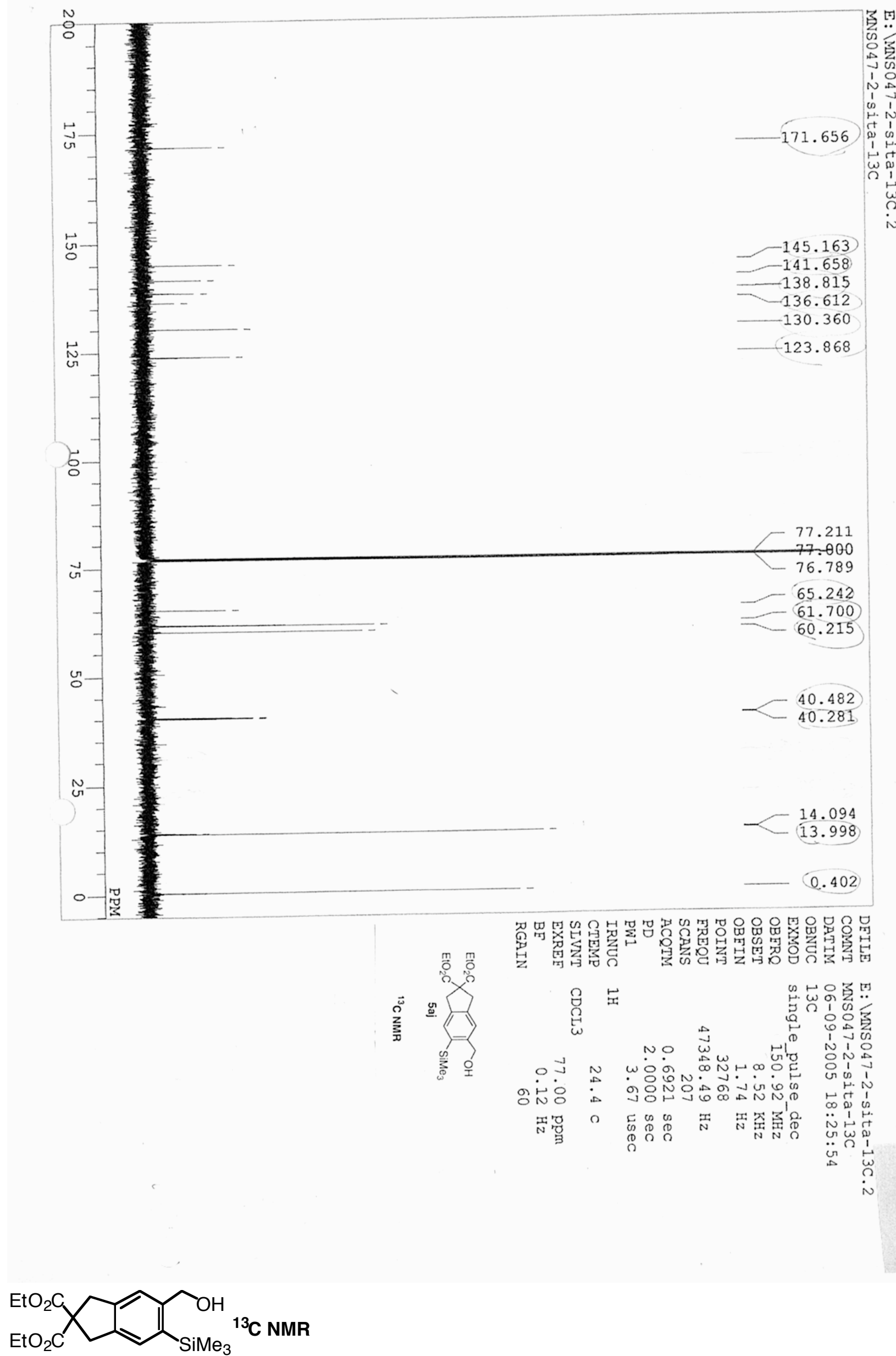

5aj 

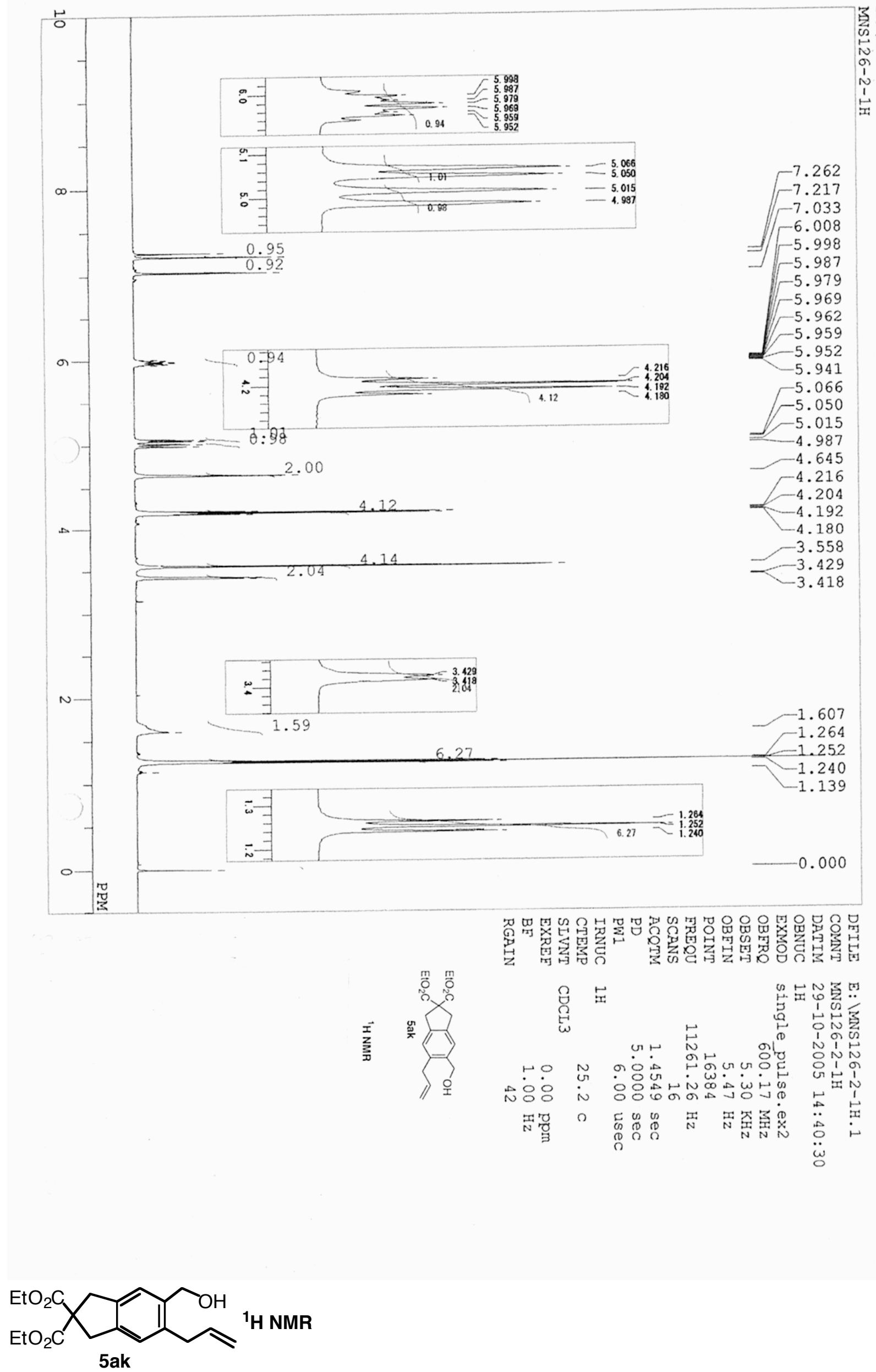

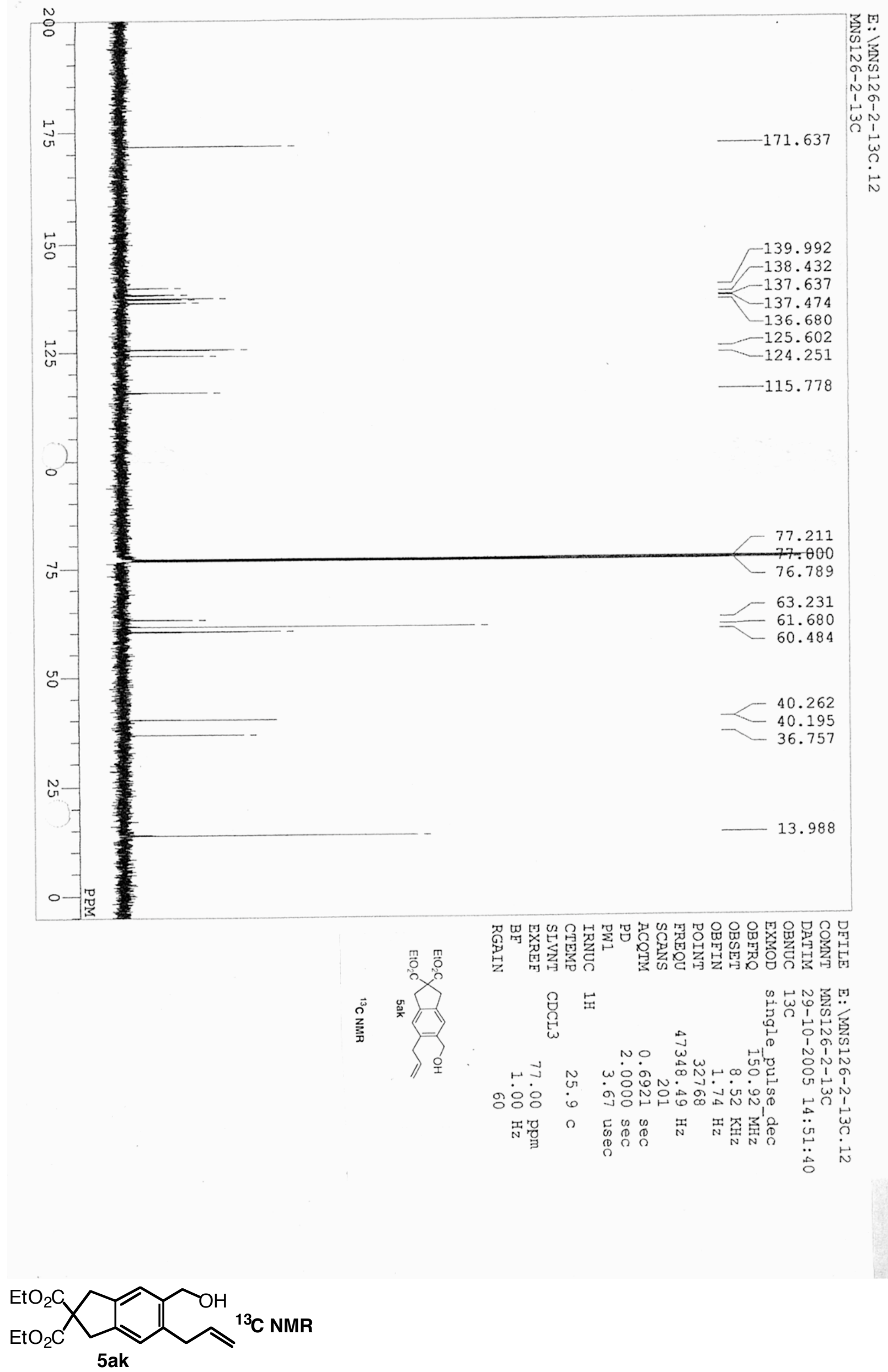

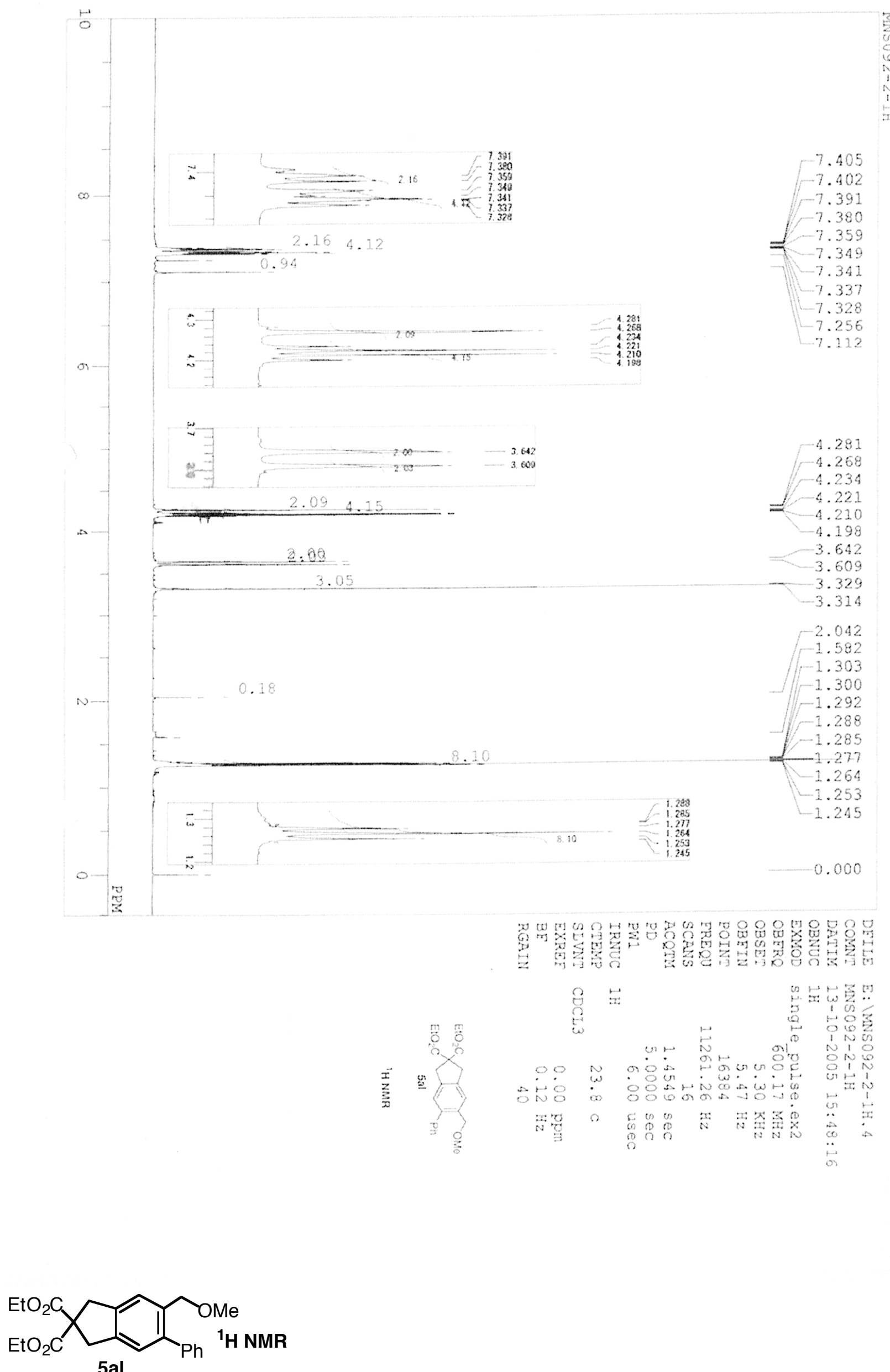

Page: 32 

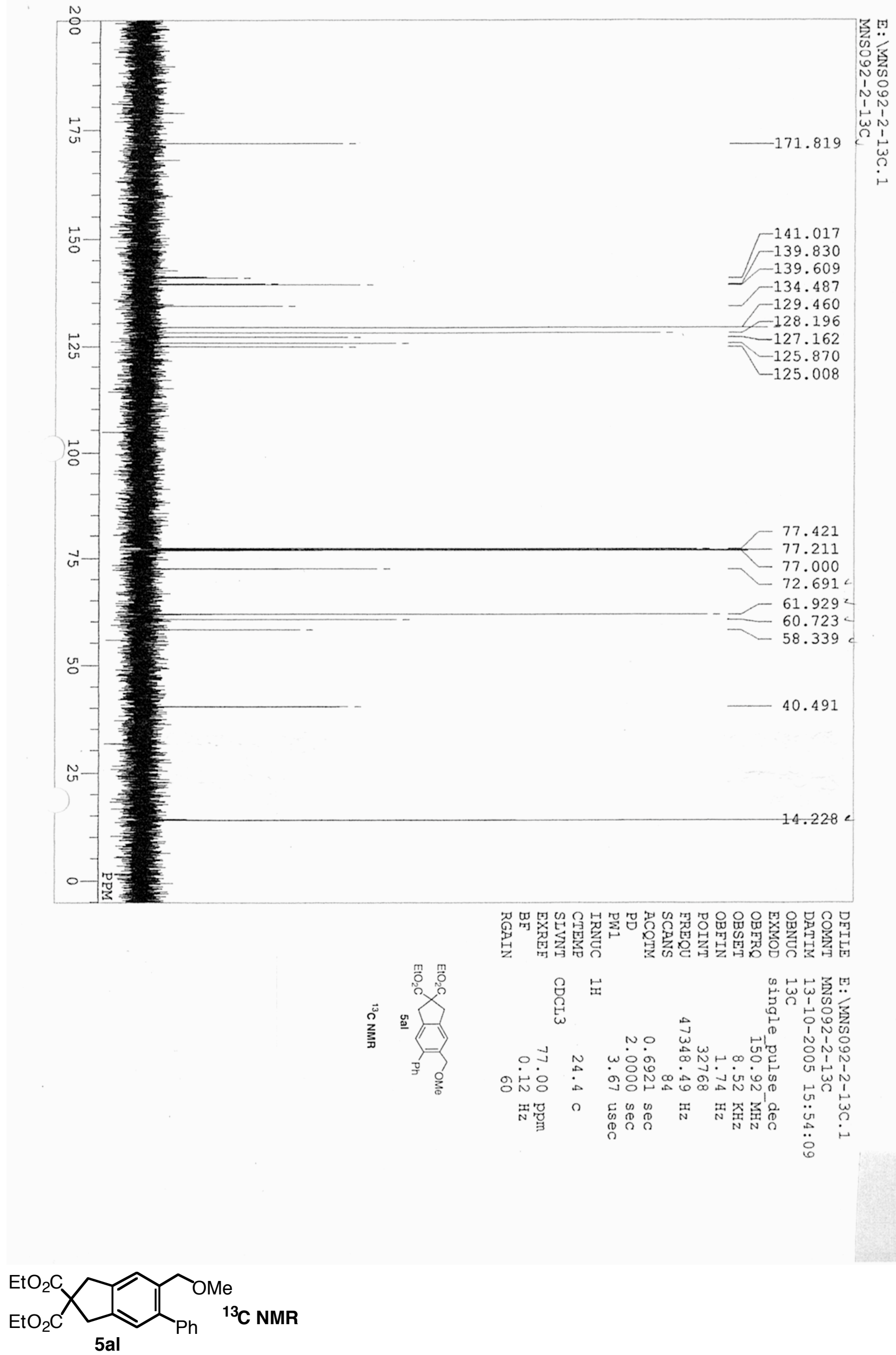

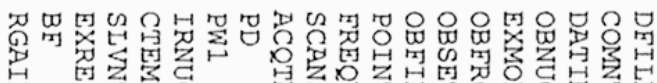

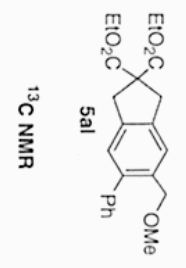

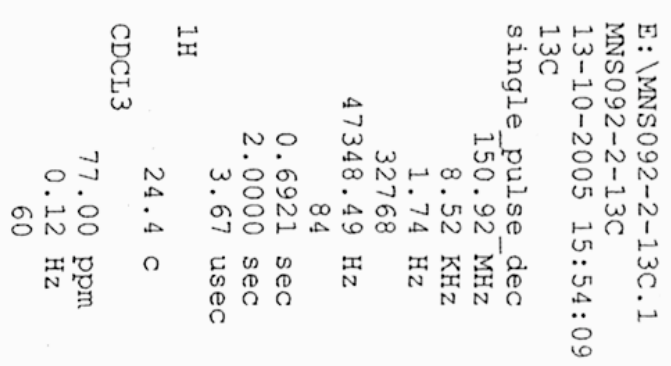



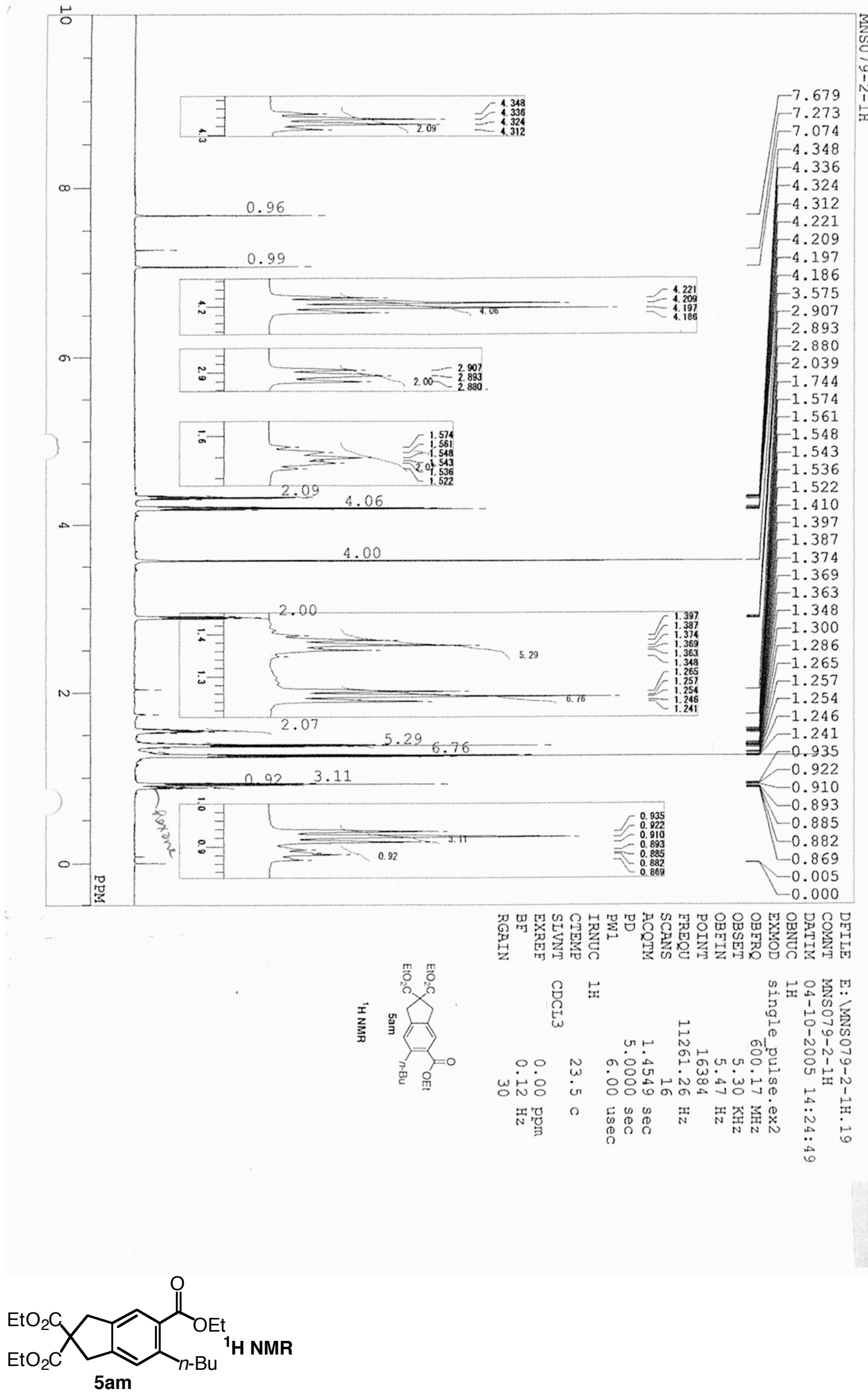

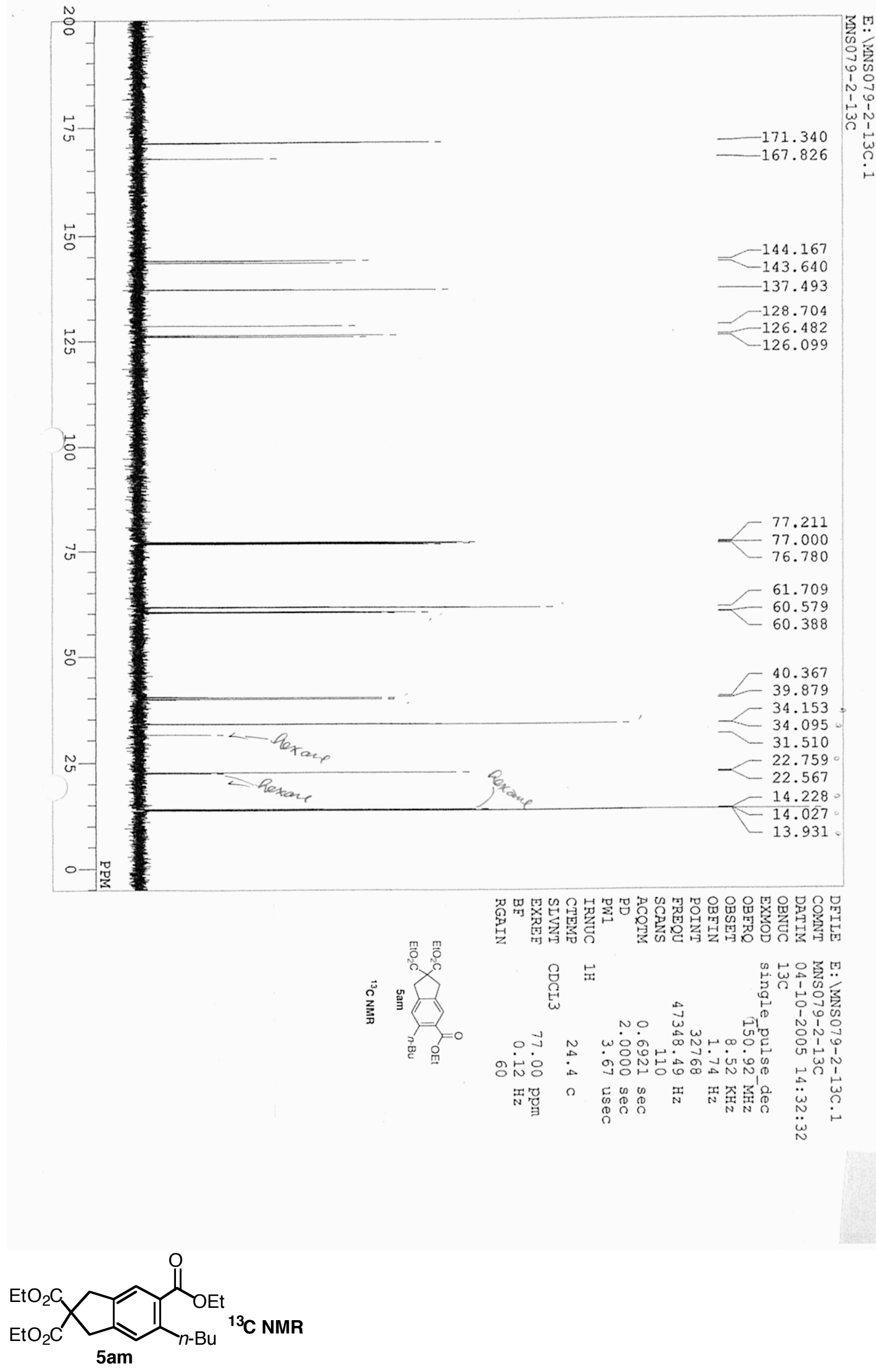